José Martínez-de-Toda, S.J.

Director del Centro Interdisciplinar para la Comunicación Social

Pontificia Universidad Gregoriana - Roma

\title{
La espiritualidad del comunicador cristiano
}

La comunicación religiosa a través de los medios tiene problemas.

El porcentaje de tiempo y espacio de los medios, dedicado a temas religiosos, ha bajado a lo largo de las últimas décadas. Esto ha sido ocasionado, entre otras razones, por la creciente secularización. ¿Dónde están los comunicadores católicos, que luchan en los medios seculares por una presencia mayor de temas éticos, espirituales y por un tratamiento de los diversos temas más positivo para la humanidad?

En algunos países se aprovecha cualquier ocasión para atacar a la Iglesia. Esto inhibe a los periodistas católicos de salir en su defensa. O también produce en la Iglesia silencio, apocamiento, victimismo y eventualmente nihilismo.

Están las tentaciones 'tecnológica', 'lingüística' y 'profesionista' con más preocupación por la tecnología, el lenguaje mediático y los convencionalismos llamados 'profesionales' que por el contenido. Estas olvidan promover la justicia, la verdad, el respeto, la dignidad humana, la libertad, la ética, los derechos de las minorías y de los pobres y el anuncio cristiano.

Por otra parte, hay personas de buena voluntad, que entran en los medios de la Iglesia, pero desconocen el lenguaje mediático. Tampoco conocen la teología y la espiritualidad del comunicador cristiano, que les daría una visión más profunda de por qué son comunicadores y cuál es su papel fundamental.

Finalmente, el mensaje cristiano mediático no está llegando al público. Así lo indican las investigaciones recientes entre los jóvenes, por ejemplo en Santiago de Chile (Lagomarsino y Zarzuri 1998; Martínez-de-Toda 2000a), Quebec (Martínezde-Toda 2001d).

El mismo Juan Pablo II lo reconoce el 18 de enero de 2002 y señala como causa las exigencias de la vida cristiana y las diferencias lingüísticas. Efectivamente la cultura de hoy es materialista y consumista. En cambio el mensaje cristiano es difícil, trascendente y a veces 'contracultural', es decir, va contra la tendencia cultural del momento. A pesar de todo ha sido aceptado desde su inicio, se ha extendido por el mundo y no siempre por el peso de las armas.

Pero además el lenguaje teológico es diferente del lenguaje mediático. El Cardenal Ratzinger y el ahora Cardenal Walter Kasper lo reconocieron el 8 de octubre de 2000 a propósito de los debates sobre el Dominus Jesus (entrevista en "Frankfurter Allgemeine", publicada en L'Osservatore Romano, 8 octubre 2000, y en Alfa y Omega, Arzobispado de Madrid, 26-X-2000). 
Estos problemas levantan interrogantes: ¿Cómo debe ser el comunicador cristiano? ¿Cuáles deben ser sus características? ¿Qué motivaciones debe tener? ¿Qué vida interior debe tener para que pueda comunicar eficazmente?

Aquí se presenta la espiritualidad como algo que debe impregnar toda la misión de comunicador. Ella le permitirá conocer las razones teológicas de por qué debe comunicar no solo el mensaje cristiano, sino cualquier tipo de mensaje. Al mismo tiempo le hará vivir su vocación no solamente a nivel teórico, sino enraizada en su quehacer. Es una espiritualidad que animará toda su vida. Sin espiritualidad le faltará la convicción de su mensaje. Ella es elemento fundamental de la comunicación cristiana y el alma del comunicador cristiano. No puede haber una dicotomía entre la profesión de comunicador y su vida interior. Ambas deben enriquecerse e integrarse mutuamente.

¿Qué agua puedo beber de un vaso, si está vacío? El público no puede apropiarse el mensaje cristiano, si el comunicador está vacío, sin convicción. Un periodista con una espiritualidad intensa será un gran comunicador cristiano.

Conviene distinguir, al menos conceptualmente, el tema de la espiritualidad que se tratará aquí, de otros temas, como ‘qué' y 'cómo' se debe comunicar. En la práctica están muy relacionados. Una espiritualidad fuerte en un comunicador cristiano influirá en que el contenido de su mensaje sea más auténticamente cristiano. Asimismo, una espiritualidad fuerte hará que los mensajes sean transmitidos con más convicción.

Los núcleos del presente trabajo son teología, espiritualidad, comunicación y contexto. Se trata de unir estos elementos. De la teología de la comunicación brotará una espiritualidad que enriquecerá su comunicación, y le ayudará a vivir una vida cristiana conforme con el contexto y con el mensaje que quiere dar. La espiritualidad es el puente entre teología y comunicación.

Primero se explicará lo que se entiende por 'espiritualidad' en general, sus características, el contexto en que se halla la espiritualidad latinoamericana y la necesidad que el comunicador cristiano tiene de desarrollar su propia espiritualidad (I).

Después se buscarán los elementos teológicos en que se basa la espiritualidad del comunicador (II). Se verá el camino espiritual del comunicador y las características más concretas de la espiritualidad del comunicador cristiano (III). Se indicarán las tentaciones más comunes en el comunicador cristiano (IV). Ellas obligan a buscar las prioridades espirituales (V). Finalmente se especificará cómo la espiritualidad del comunicador cristiano se da en la práctica (VI).

\section{CONCEPTO DE ESPIRITUALIDAD. BASES DE LA ESPIRITUALIDAD DEL COMUNICADOR CRISTIANO}

El comunicador cristiano busca su propia espiritualidad. Pero hay diversos enfoques sobre espiritualidad.

\section{1. ¿Qué es espiritualidad?}

El término espiritualidad recientemente ha sido adoptado por protestantes, por académicos de otras religiones, y aun por secularistas y marxistas (Principe 1993: 931). También ha comenzado a usarse a nivel más popular. Al ser una palabra usada 
también fuera del ámbito estrictamente religioso, se le ha dado una gran variedad de acepciones (Larkin 1998: 1170; Matanic 1983). Su concepto está muy relacionado con términos como religión, sagrado, secular...

El enfoque de los estudios religiosos seculares examina la espiritualidad desde un ángulo estrictamente académico sin un compromiso de fe (cfr. Principe 1993: 934). Para definir lo espiritual, lo sagrado y la religión, tales estudios acuden a diversos autores, como Marx (1963: 41-42, 84; Das Kapital, pp. 84-85), Freud (1975: 58, 321; 1985: 195-204, 213, 231), Durkheim (1975: 178), Weber (1968: 408-409, 424, 609, 630) y Brugger (1988). Otros se lanzan a dar su propia definición de espiritualidad (Berman 1981; Hardy 1984; el chamán cuzqueño -Watupakeri- Darikiking Alejandro Jahuanchi 1998; Gyatso, el 14º Dalai Lama, hablaba en 1996 de una espiritualidad laica).

Hay varios estudios sobre jóvenes, medios y espiritualidad. Fueron hechos en Santiago de Chile, Quebec, Australia, Italia, Holanda, el Reino Unido y Estados Unidos (cfr. Martínez-de-Toda 2001). A pesar de la diversidad geográfica, presentan algunos rasgos comunes.

Ellos muestran que hay un florecer de experiencias espirituales, sagradas y religiosas de los jóvenes al contacto con los medios. La nueva religiosidad se desliga de dogmas rígidos y de instituciones religiosas y prefiere la psicología y la religiosidad oriental (Sudbrack 1988: 9). Espiritualidad es una de las palabras preferidas de la nueva religiosidad (Ferguson 1981). Las diferencias en edad marcan también notablemente las diferencias en espiritualidades.

Algunos programas de TV pueden ser espirituales y no religiosos, y al revés. En algunos casos lo sagrado se refiere solo a valores humanos, como la dignidad humana. Lo sagrado se halla en situaciones-límite, y lo pueden proporcionar películas, programas de deportes, de publicidad, de talk-shows sobre problemas de la gente y aventuras de riesgo. Para otros la realidad última es el sonido, la armonía de la realidad (Berendt 1983: 179s).

H. Mynarek (1983: 1, 21, 83-85, 239-241) propuso sus conclusiones en algunos de estos eslóganes, que representan las etapas cronológicas de la nueva religiosidad:

$1^{\text {a } ~ " R e l i g i o ́ n ~ m o n o t e i ́ s t a, ~ n o ; ~ r e l i g i o s i d a d, ~ s i ̂ " . ~ 2 ~ 2 a ~ " I g l e s i a, ~ n o ; ~ J e s u ́ s, ~ s i ̂ " . ~} 3^{\text {a }}$ "Jesús, no; Dios impersonal, sî". 4a "Religión sin Dios". 5 "La religión ecológica será la religión del futuro”.

Hay grandes diferencias en cómo es concebida la espiritualidad por los estudios religiosos seculares y por los estudios religiosos basados en la fe cristiana. Los resultados anteriores representan un desafío para estos últimos. Si más y más gente está buscando una nueva religiosidad, ¿dónde se equivocaron los cristianos? ¿Cómo vencer el aparente choque entre la religión vieja y la nueva, entre los teólogos y los encargados del entretenimiento de los medios? ¿Cómo puede la Iglesia cumplir hoy su misión de predicar a Cristo en la actual cultura mediática y a través de los medios masivos? ¿Qué espiritualidad debe tener el comunicador cristiano, de forma que su vida interior y su predicación del evangelio tengan en cuenta las nuevas tendencias de la espiritualidad juvenil frente a los medios? ¿Cómo compaginar una espiritualidad con fe en Dios con la de los estudios seculares? 
Aquí no se trata de responder a todas esas preguntas por completo. Pero se tendrán en cuenta para el tratamiento del tema. Antes que nada se necesita un diálogo respetuoso y crítico al mismo tiempo. Esto significa que el cristiano debe estar dispuesto a aprender de la religiosidad nueva.

Concepto de espiritualidad en el presente estudio

En la Iglesia Católica se ha estudiado mucho la espiritualidad cristiana y las diversas escuelas de espiritualidad existentes en ella: benedictina, franciscana, de jesuitas... Donde primero se usó el término fue en Francia (espiritualité), según el alemán Sudbrack (1988: 97-98).

El enfoque usado aquí es el de la espiritualidad dentro de una comunidad de fe, que responde a una revelación aceptada como normativa. Tal espiritualidad con fe incide en las áreas de actitudes, conductas y conocimientos y se acerca a un plano real y experiencial.

En general "espiritualidad" se entiende como una existencia religiosa comprometida. El elemento más importante de esta espiritualidad con compromiso de fe es la experiencia personal de Dios. De esa experiencia vienen un entendimiento y una comprensión también personales de esa relación con Dios, así como una actitud básica, práctica y habitual, que gobierne la vida del sujeto (Alphonso 1994: 11). Y así hay una espiritualidad hindú, budista, musulmana y cristiana.

La espiritualidad cristiana es la forma en que una persona, que está animada por la presencia viva y por la acción del Espíritu de Cristo, reacciona y actúa habitualmente de acuerdo a Él (Alphonso 1994: 14-15). De esta forma la espiritualidad cristiana abarca toda la persona humana (cuerpo, alma, espíritu) (Principe 1993: 932). Para S. Pablo una persona es espiritual, cuando todo su ser y toda su vida están ordenados, dirigidos e influenciados por el Espíritu de Dios (Pneuua QeouPneuma Theou; Spiritus Dei - ver 1 Cor 2:12, 14) (cfr. Principe 1993: 931), por su aliento, que es vida. Es la actualización del espíritu de Jesús (Sobrino 1985: 8). La renovación de la teología bíblica y una mayor conciencia de la pneumatología en Occidente ayudaron a ver la importancia de S. Pablo (Rom 8, 29, 16-17) en la espiritualidad.

Además de este enfoque paulino de espiritualidad cristiana, hay también otros enfoques muy diversos entre sí. La diversidad mayor se dio entre protestantes y católicos, especialmente en lo relativo a gracia/obras, palabra/sacramento, y eclesiología. La espiritualidad católica actual se deriva del Vaticano II (Principe 1993: 933). Dentro de la Iglesia Católica, prescindiendo de las diversas escuelas, hay también diversos tipos de espiritualidad.

Espiritualidad es el encuentro entre el Espíritu Santo y nuestro espíritu con sus aspiraciones, problemas y su contexto particular. La espiritualidad surge del encuentro de la experiencia con la gracia de Dios. Este encuentro es un contacto vital que nos impacta, nos marca y trata de transformar nuestra vida. El contacto puede ser algo personal con Dios, con personas de Dios, con libros, música, filmes, programas de los medios, eventos y cosas que se refieren a Dios... El test de una espiritualidad es una vida integrada con amor y obras.

Haughey (1973), teniendo en cuenta los medios, dice que hay tres tipos de espiritualidad entre los católicos: la institucional (son leales a la doctrina de la 
jerarquía, y no se fían de las fuentes seculares), la pneumática (están preocupados por su propio crecimiento espiritual y se fían más de los libros que de los medios; por ejemplo, los carismáticos y los religiosos/as de clausura;), y la autogénica (estimulan la democratización dentro de la Iglesia, y piensan que en general los medios seculares presentan sin prejuicios a la Iglesia) (Cfr. Thorn 1996: 102-103).

\section{Cómo debe ser la espiritualidad}

Varios autores ofrecen recomendaciones generales sobre cómo debe ser la espiritualidad cristiana hoy. En El Salvador Jon Sobrino (1985) dice que "vida espiritual significa vivir la historia con espíritu de apertura, de disponibilidad, de fidelidad... La verdadera vida espiritual implica un espíritu de santidad, que no es otra cosa que el compromiso real con los pobres".

En Italia Goffi (1987) compara la espiritualidad del pasado, la de hoy y la que se prevé en el futuro. Aquella consistía en una exposición doctrinal sistemática, que tendía a señalar de forma completa cómo se alcanzaba la santidad de forma progresiva. En cambio la espiritualidad contemporánea prefiere partir de la propia experiencia existencial y vocacional, intentando imprimir en ella una configuración evangélica propia. Pero señala que la espiritualidad del mañana será más ecuménica, o sea más católica (universal) de hecho, pues tratará de comprender la multiforme riqueza espiritual que el Espíritu suscita.

En Estados Unidos Au (1989) considera que la espiritualidad debe ser holística e integrada. Debe buscar convertir la fe de una persona en un elemento dinámico que afecte todas las dimensiones de su vida cotidiana, de forma que no sea meramente un asentimiento intelectual de verdades abstractas.

Finalmente los chilenos Arroyo, Silva y Verdugo (1992) plantean que toda fe requiere complementariamente una ideología. Ellos la entienden como un sistema de mediaciones para instaurar en la realidad los valores que ella representa. Esto exige estar alerta sobre el uso que otras ideologías pueden hacer de la religión misma. Esta puede ser utilizada como instrumento para defender o implantar un determinado orden social. En este caso "la espiritualidad misma alimentará las palabras y la acción y desde allí se hará una lectura de las ideologías".

El reto es aplicar estas recomendaciones al trabajo del comunicador cristiano en los medios. En el último capítulo se indicarán algunas.

\section{Contextos de la espiritualidad latinoamericana}

La espiritualidad tiene en cuenta el contexto del sitio donde se halle el comunicador. El de América Latina en términos generales es como sigue:

3.1 Contexto económico: Hay una situación de pobreza de las mayorías. Estas se sienten arrastradas por el modelo neoliberal y por la globalización sin perspectivas de poder reorientarse hacia un modelo más humano de desarrollo.

3.2 Contexto cultural. Las nuevas tecnologías y los modernos cambios culturales están influyendo muy fuertemente en los nuevos lenguajes y símbolos y en las 
nuevas formas de pensar y sentir. La cultura de América Latina es una cultura mestiza e híbrida, característica del inmigrado a la ciudad, sujeto también a la influencia de la cultura contemporánea globalizante.

Esta cultura contemporánea se está haciendo sentir ya con fuerza. He aquí alguna de sus características: es mediática, fragmentaria (posmoderna). El elemento histórico pesa poco. Lo que se quiere es libertad. Predomina lo subjetivo, pragmático y consumista. Lo importante es las relaciones que se tienen. Hay una pérdida de identidad por el desplome de modelos del pasado. Es globalizante, donde lo que predomina es la competencia y la eficiencia. Es pluralista cultural y religiosamente. Es secularizada. Grupos específicos, como los jóvenes, tienen su subcultura. (Ver ampliación de estos conceptos en Martínez-de-Toda 2001a).

3.3 Contexto religioso: Representa el encuentro de tres grandes tradiciones:

En las diversas etnias indígenas hay una comunión entre lo humano, lo cósmico y lo espiritual. Lo espiritual y lo trascendente son vistos como la esencia de la armonía cósmica en el ciclo vida-muerte. Hay un sentido de misterio y de significado simbólico en toda realidad. Los ritos de la vida tienen una gran importancia espiritual. La cultura indígena religiosa es mítica, oral y colectiva. Esto se da especialmente en Bolivia, Perú, Ecuador, Guatemala y México.

Los europeos del Sur trajeron un catolicismo postridentino, literal, jerárquico y sacramentalista con su uniformidad doctrinal y disciplinaria. Los españoles se identificaban fuertemente con el símbolo de la cruz, por la que habían luchado en su país durante ocho siglos contra la luna árabe en creciente (Martínez 1993: 474). Ellos trajeron consigo al nuevo continente devociones populares y expresiones dramáticas para sus fiestas religiosas, la participación comunal, un idealismo ascético y místico y el humanismo de la contrarreforma. Desde el s. XIX y parte del XX se nota la presencia crítica del positivismo (Augusto Comte 1798-1857) con gran incidencia en la educación, la política, el derecho, el tratamiento público de lo religioso y la información. Esto se dio especialmente en Venezuela, México, Argentina, Brasil, Chile, Uruguay, Perú, Bolivia y Cuba.

Los africanos aportaron su animismo, especialmente en partes del Brasil y el Caribe.

\section{Características de la espiritualidad latinoamericana}

Actualmente la espiritualidad latinoamericana tiene las siguientes características comunes:

a) Hay un aprecio profundo por la dignidad de la persona. Dios se preocupa de todos, especialmente de los niños, los pobres, los enfermos y los ancianos.

b) Da un gran valor a las relaciones interpersonales dentro de la familia y de la sociedad. La familia es la primera en transmitir las creencias religiosas, los valores y las tradiciones (Martínez 1993: 475).

c) Los católicos no se sienten completamente a gusto en la Iglesia Católica, al menos según un estudio hecho en Venezuela en la década pasada. Esto ocurría a pesar de que entonces la credibilidad hacia ella era la más alta entre todas las instituciones. Los informes de la Conferencia Episcopal Venezolana para los 
sínodos de 1977 y 1984 reconocían: "Nuestro pueblo no rechaza la Iglesia, la quiere, pero no 'se siente' Iglesia". Por su parte en EE.UU. "la gran mayoría de los hispanos se sienten distantes o marginados de la Iglesia Católica" local (The National Pastoral Plan for Hispanic Ministry, Origins, p. 451).

d) Se relaciona profundamente con el simbolismo ritual y la sacramentalidad.

e) Tiene devociones populares muy enraizadas, como la del Cristo crucificado, espejo de los sufrimientos propios. Aun Lagomarsino y Zarzuri (1998: 29), de los estudios religiosos seculares, reconocen la importancia de la Biblia y de Jesús en América Latina. Hay gran veneración por la Virgen María como madre espiritual y por los santos como poderosos intercesores. Las fiestas religiosas de la Navidad, Reyes y Semana Santa se celebran con representaciones teatrales y cantos especiales.

f) Es una Iglesia profética y evangelizadora (CELAM-Medellín 1968, CELAMPuebla 1979, CELAM-Sto. Domingo 1992), pero también evangelizada por los pobres. La Biblia ha sido especialmente meditada y comentada en las comunidades eclesiales de base. Son especialmente importantes la liberación de Egipto, las Bienaventuranzas y el Juicio Final. De ella se ha sacado la opción preferencial por los pobres. La teología de la liberación ha producido su propia espiritualidad de liberación, basada en la justicia social (Sobrino 1985; 1998).

g) Es heterogénea con diversidad de tendencias y movimientos eclesiales, como carismáticos, etc. Se mueve en un contexto secular, con espiritualidades como la de New Age.

\section{ELEMENTOS TEOLÓGICOS DE LA ESPIRITUALIDAD DEL COMUNICADOR CRISTIANO}

El espíritu es ante todo 'viento', 'fuerza' (spiritus, pneuma). La espiritualidad cristiana es como una cascada de agua con su fuente principal y sus derivaciones. También es como un árbol con raíces, tronco, ramas, flores y frutos. Tal es su fuerza y su complejidad. Pero todo está relacionado entre sí.

Inicialmente hay una gracia, que es la fuente (o raíz) de donde viene todo. Esta gracia o carisma es recibida por una persona o por una institución. Da pie a diversas espiritualidades, como la franciscana, la ignaciana, la de los diversos movimientos eclesiales...

Se distinguen dos tipos de carisma: el 'funcional', que va orientado a un servicio concreto. Por ejemplo, una congregación religiosa determinada se funda para cuidar enfermos, otra a la educación... En cambio el carisma 'troncal' es algo central, de lo que no se puede prescindir. Por ejemplo, la Compañía de Jesús se funda orientada hacia fuera para evangelizar el mundo, no se cierra en sí misma como las Órdenes monacales.

En el caso de la comunicación la gracia fue recibida a través del Vaticano II. Esta fuente se halla más concretamente en Lumen Gentium (1964) y en Gaudium et Spes (1965), los dos documentos más importantes del Concilio. Más abundantemente se halla en Communio et Progressio (1971), documento posterior al Concilio, 
pero que este había mandado elaborar en Inter Mirifica (1963), y que por lo tanto se puede considerar dentro del espíritu del Concilio. Su idea fundamental es la autocomunicación de Dios, que se da a sí mismo a la humanidad. Es algo central al evangelio. Se trata, por lo tanto, de un carisma troncal. Sin embargo, también se puede considerar como 'funcional', pues trata de estimular la comunicación entre todos, especialmente a través de los medios masivos.

\section{La espiritualidad del comunicador se basa en la teología de la comunicación}

Cada idea y cada acción del cristiano tienen presupuestos teológicos. La calidad de mi trabajo como comunicador depende de los principios de teología y espiritualidad que informen mi actividad. Los problemas que encuentre en mi camino serán solucionados según la teología que tenga.

La espiritualidad se basa en la teología, aunque algunos discuten en qué forma se relacionan los estudios de espiritualidad y de teología (por ejemplo, Principe 1993: 935). Hay diferentes estilos de teología: el de fides quaerens intellectum (scientificum) (propia de la teología académica) (S. Anselmo de Canterbury), el de fides quaerens iustitiam socialem (propia de la teología de la liberación), el de fides quaerens adorationem (propia de la liturgia) (O'Collins 1993: 16-19)... Estas teologías determinan diferentes tipos de espiritualidad. ¿Podríamos añadir un cuarto estilo: el de fides quaerens intellectum (communicationis cum Deo et hominibus)?

Teología en este contexto sería una reflexión sistemática sobre la comunicación existente entre Dios y la humanidad. En general la teología capacita al hombre a ver el mundo con los ojos de Dios. Es como la medicina, que da la capacidad al médico de saber lo que le pasa al enfermo solo con verlo y examinarlo.

Algunos teólogos usan el método deductivo. Aquí se prefiere el inductivo o antropológico, según el cual se parte de la realidad humana comunicacional para ser interpretada a la luz de la teología. La comunicación humana es un fenómeno antropológico, filosófico y social. Es importante en la vida y en la fe.

La relación sustancial de la comunicación con la teología es con la historia de la salvación, que es el desarrollo de la revelación o comunicación entre Dios y el hombre hacia una comunión aún mayor.

Conviene distinguir entre una 'teología de los instrumentos de comunicación social' (Communio et Progressio 6, 7, 9, 12-17) y una 'teología de la comunicación'(CP 8, 11, 18). Esta última sería una lectura de la historia de la salvación y del misterio cristiano, en cuyo centro está la comunicación (o 'autocomunicación' de Dios), que es la revelación.

La espiritualidad del comunicador cristiano es inicialmente cristológica, pero Cristo nos lleva en seguida a la Trinidad. Así pues, es esencialmente y sobre todo trinitaria. En primer lugar, porque "toda espiritualidad auténtica cristiana es ipso facto trinitaria... La doctrina de la Trinidad constituye el corazón y el alma de la espiritualidad cristiana" (Lacugna y Downey 1993: 968). Pero lo es especialmente en el caso de la comunicación.

En consecuencia, "El Dios invisible, en la riqueza de su amor, habla a los hombres como a amigos" ( $D V 2)$. Esto significa que la teología tiene como punto de 
partida, como objeto, como centro y como meta, un acontecimiento comunicativo: aquel en el que Dios se da al hombre y lo invita a participar a la plenitud de su vida divina. Por tanto, la comunicación forma parte integrante y esencial de la revelación cristiana. Todo lo que se ha dicho en la Iglesia sobre revelación, se refiere también a la comunicación. La Trinidad está siempre en comunicación entre sí y con nosotros y por eso es maestra y madre de la comunicación.

Asimismo está muy relacionada con los demás misterios de la fe (CP 11).

Por tanto, el eje principal (o tronco) de esta espiritualidad es Jesucristo, el "perfecto comunicador" en el misterio pascual ( $C P 11)$, a quien los hombres vieron y tocaron. Él nos habla de la Trinidad y nos introduce a ella, eternamente autocomunicante. Por lo tanto, la espiritualidad del comunicador es sobre todo cristológica, pero con referencia a la Trinidad (Sachs 1990: 9). El tronco tiene muchas facetas (todas son donación de Dios a la humanidad). Ellas representan la Creación, la Encarnación, la Eucaristía, la Cruz, la Resurrección, Pentecostés y la Iglesia.

\section{La teología de Communio et Progressio (1971)}

La mayor parte de la teología propia del comunicador cristiano se halla en $C P$.

Esta Instrucción Pastoral es el documento de la Iglesia más importante en este campo. Baragli (1971: 16) dice que "en su conjunto la $C P$ se puede considerar como la Carta Magna católica de las comunicaciones sociales". La $C P$ se hizo por un mandato expreso de los Padres Conciliares recogido en el IM. Está muy en consonancia con el resto de los documentos del Vaticano II. Hoy día hay elementos para enriquecerla y habría que incluir una reflexión teológica sobre la nueva cultura mediática. En ella se echaron las bases para una teología de la comunicación.

He aquí un breve resumen de los NN. 1, 6-18, donde se hallan los elementos doctrinales. Se utiliza por razones didácticas como eje la historia de la salvación:

1. Plan de Dios sobre los medios: La historia de la salvación tiene tres pasos principales: creación $(C P 7)$, caída $(C P 9,10)$ y redención $(C P 10)$. Es Dios quien inicia la comunicación con los hombres con la creación: los medios masivos son una participación en el poder creador de Dios ( $C P$ 7). Ellos son dones de Dios (Pío XII, 1957). Ellos, según designio de la divina providencia, unen a los hombres para que colaboren con su divina voluntad ( $C P 2$ ). Más aún, son necesarios para la unión de la humanidad ( $C P$ 6). Con ellos el hombre, hecho a imagen y semejanza de Dios, participa en la creación y construcción de la ciudad terrena ( $C P 7)$. Los medios ayudan a la comunicación social, esta lleva a la unión y la unión contribuye al plan de Dios.

La comunicación lleva a la justicia, a la paz, a la benevolencia, a la mutua ayuda, al amor. Los objetivos ideales de la comunicación social son comunión y progreso $(C P 1)$. Los medios son una de las mejores formas de llegar a la comunión ( $C P$ 12). Los medios de comunicación serán buenos si ayudan al bien común. Debe haber un equilibrio entre informar, educar y entretener ( $C P$ 16). La comunicación debe ser ajustada a la sinceridad, honradez y verdad ( $C P$ 17). 
2. El pecado. Si los medios generan males, se debe al pecado. El pecado rompe la comunión. La solución es liberarse del pecado y volver a la comunión con Dios (CP 9).

3. Cristo es el perfecto comunicador. La comunicación humana viene de la comunión trinitaria. Este es su modelo ( $C P$ 8). Dios se comunica con el hombre en la Encarnación. Por ella se incultura. La Eucaristía es la forma de comunión más perfecta: es comunión entre Dios-hombre, y de los mismos hombres entre sí. Después Cristo muerto y resucitado libera al hombre, le comunica su gracia y le invita a participar en su vida divina. Así Cristo realiza una comunicación perfecta, que es la entrega de sí mismo por amor. Cristo nos comunica su Espíritu, el Espíritu Santo, principio de toda unión. El Evangelio promueve la fraternidad de los hijos de Dios. (CP 13). Por todo esto Él es el fundamento de la comunicación y el primer modelo. También es su promotor en la tierra $(C P$ $10)$.

De esta forma Él restaura la comunión con Dios y entre los hombres. La historia de la salvación tiene en su centro la comunicación de Dios. Esta historia es el desarrollo de la comunicación entre Dios y el hombre hacia una comunión aún mayor.

La $C P$ nos da tres precisiones de Jesús como Perfecto Comunicador: la globalidad, es decir, cuando se habla de Cristo comunicador no basta considerar la autoridad de las palabras, sino los gestos, el modo de vivir y sobre todo la capacidad de darse a los demás ( $D V 2)$; la condescendencia, es decir, Cristo se adaptaba a la forma de hablar y pensar de los de su tiempo (CP 11); y su finalidad es realizar la comunión auténtica (CP 8).

4. Cristo en la Iglesia-sacramento hace que caminemos hacia la unión definitiva, cuando Dios esté todo en todos ( $C P$ 11). Esta comunión, que puede promover la comunicación social, es también el objetivo de la Iglesia, Pueblo de Dios. La Iglesia es señal e instrumento de la unión Dios-hombre y entre los hombres (CP 18).

Como se ve, la $C P$ contiene elementos de teología trinitaria, cristológica, eclesiológico-sacramental e histórico-soteriológica $(C P$ 8, 15). En ella hay un tentativo de equilibrio entre la teología de los instrumentos de comunicación social (CP 6, 7, 9 y 12-17) y la teología sistemática de la comunicación $(C P 8,11,18)$.

Con este documento la Iglesia llega a una nueva conciencia, lejana de los titubeos y del miedo a los efectos negativos de los medios y a los 'daños que a menudo su mal uso ha traído a la humanidad' (IM 2, EN 1/245). La CP incluye aspectos culturales de la comunicación al hablar de la Encarnación.

Tres niveles de comunicación

En la $C P$ se pueden distinguir tres niveles de comunicación (Martínez-de-Toda 2001c: 17):

- $\quad$ El modelo ‘transmisión' y linear, que identifica comunicación con información y persuasión.

- El modelo 'comunión', que se basa en que la comunicación es creación compartida de significados. Va más allá de la información. 
- El modelo de la 'autocomunicación', que es donación de sí mismo por amor. Este es el nivel superior. Un concepto nuevo de comunicación, más exigente y generoso que los considerados en las ciencias de la comunicación, pero presente en la $C P(11)$. No es algo teórico. Se realizó plenamente en Jesús, el Perfecto Comunicador, que se nos dio. Y así participamos en la vida divina. Poner en práctica este concepto mejorará notablemente la comunicación.

\section{De la teología a la espiritualidad del comunicador}

“Para qué sirve la teología?” se preguntaba S. Roberto Bellarmino. Y respondía así en su Catecismo: "para conocer, amar y servir a Dios en este mundo y después gozar de Él para siempre en el otro”. (Boff 1998: 396, 398, 406 edic. en portugués).

Efectivamente se hace teología para conocer a Dios (ciencia teórica). Se le conoce para amarlo (ciencia afectiva) y se le ama practicando lo que Él quiere (ciencia práctica), hasta hacer y ser como Él: comunicación. Así el intellectus fidei se hace affectus fidei, que a su vez se hace operatio fidei.

Esto permite distinguir dos tipos de teología: la especulativa y la práctica. La primera es la ciencia teórica, por ejemplo, la teología dogmática. El objetivo inmediato (directo y próximo a nivel teórico) es conocer a Dios. La escuela tomista se puede considerar como ciencia teórico-práctica, pero más teórica que práctica.

La teología 'práctica' se refiere al objetivo terminal (indirecto, mediato) de la teología. Su finalidad principal y absoluta de tipo práctico es amar y servir a Dios, poner en práctica su voluntad y gozarle en la gloria. Es un objetivo al servicio de la vida espiritual y de la pastoral. Por ejemplo, la teología moral. Y así la escuela franciscana es práctica-teórica, pero más práctica que teórica: es una ciencia afectiva.

La teología (práctica) debe estar al servicio de la vida espiritual y de la pastoral. En el primer caso, sus quehaceres son: discernir la experiencia espiritual, introducir mistagógicamente a tal experiencia y ceder el paso a la devoción y a la mística, andando más allá del logos. Es aquí donde aparece la espiritualidad del comunicador.

La teología como servicio a la pastoral debe tener una orientación evangelizadora. Inclusive algunas disciplinas teológicas deben privilegiar la función pastoral desde el punto de vista temático y sistemático. Por ejemplo, es conveniente que el curso principal de teología fundamental en su globalidad vaya a privilegiar una orientación explícitamente pastoral, de forma que ofrezca efectivamente una teología-para-pastores. (Boff 1998: 65). Así el teólogo podrá comunicar mejor el mensaje cristiano.

La teología bien desarrollada lleva a un contacto y a un encuentro con Jesucristo (Ef. 3, 14-19). Una sólida teología trata de ser coherente en la vida personal y cotidiana. La teología guía la vida humana según los valores dados por Dios. La teología y la espiritualidad son interdependientes.

Es un servicio 'arquitectónico', que mira a la construcción del cuerpo de Cristo en su conjunto.

La teología trata de comunicar también una sabiduría para la vida en valores, orientaciones, horizontes para vivir, pensar y decidir.

Es verdad que la teología sufre hoy día los efectos del cambio cultural. Estamos en una cultura pragmatista y activista, que huye de la reflexión personal, de la 
investigación y el estudio en general. Es una cultura materialista, hedonista y antiintelectual. Hay un fideísmo, que consiste en un creer de forma espontánea basado en la autoridad (Biblia, tradición o autoridad eclesiástica).

La tendencia 'posmoderna' trata de enfatizar la dimensión subjetiva, sensible y experiencial de la religión, lejos de doctrinas y razones. Pero así quedan al descubierto muchas insidias, como las del sincretismo espurio, la manipulación psicológica y la instrumentalización política.

\section{EL CAMINO ESPIRITUAL DEL COMUNICADOR}

¿Cómo puede adquirir el comunicador cristiano la espiritualidad mencionada? ¿Cómo internalizarla y asimilarla? ¿Cómo fortalecerla? ¿Qué itinerario práctico se puede señalar para que la actividad profesional del comunicador cristiano se enriquezca con una vida interior fecunda?

Se seguirá el esquema del Plan de Dios con alguna referencia al camino de los Ejercicios Espirituales (EE.EE) de S. Ignacio de Loyola.

\section{Saboreando el plan comunicacional de Dios \\ He aquí las etapas de su plan:}

$1^{\text {a }}$ Dios nos amó primero

Dios, antes que nada, es Amor. Y todo viene de Él. Todo ha sido hecho porque nos ama. La iniciativa del amor entre Dios y yo viene de Él. Él me amó primero. "Dios creó solo aquellos seres, de los que se enamoró" (Card. Lehman). Fui elegido por Dios para nacer en este mundo, porque Él se enamoró de mí. Soy aceptado por Dios. Me quiere como soy. En mí todo es gracia. Nací de un sueño de amor divino. Dios me tiene un amor gratuito. Está loco por mí.

\section{El hombre es comunicación}

¿Cómo y dónde comenzó la comunicación? La comunicación inter-humana viene con el hombre. El hombre es un ser abierto al otro, es sociable, es relacional, es diálogo con los demás, es un ser comunicativo. Hay en él una continua nostalgia por comunicar. Más aún la propia identidad se forma en el contacto con el otro. Uno se realiza más plenamente cuanto más vive la propia identidad en diálogo y donación con y para los otros.

\section{La comunicación humana es consecuencia de la comunicación divina}

¿Quien nos hizo comunicativos? Dios observó: "No está bien que el hombre esté solo" (Gen 3, 8). Así pues, en la comunicación todo comenzó con Él. El hombre es comunicación, porque está hecho a imagen y semejanza de Dios (Gen 1, 26). Y Dios, como Trinidad, es comunicación. La comunicación humana es símbolo y reflejo de la comunicación trinitaria. 
Dios Amor (Comunicador) está ahí en ese intercambio comunicacional, que comienza con dejar nuestro aislamiento y continúa progresivamente al relacionarse unos con otros, informarse, construir juntos un pensamiento, dialogar, comprenderse e ir creciendo en un amor y comunión, cada vez más semejante al amor de Dios. ¡Qué bello hacerse consciente de esta dinámica! ¡Qué bello vivirla internamente! ¡Qué hermoso vivir para que el proceso supere los estorbos que produce la incomunicación, y por lo tanto el alejamiento del plan de Dios!

\section{La autocomunicación de Dios con el hombre es iniciativa de Dios}

Nos encontramos delante de un hecho asombroso. El Dios Padre-Madre, el Amor Eterno, el Todopoderoso, el Acto Puro... se enamora de mí, hombre o mujer, pero ínfimo y pequeño... y decide comunicarse con una de sus criaturas...

Más aun su comunicación es una autocomunicación. Él mismo se nos da. No podíamos recibir nada mejor. La Trinidad es la fuente de la comunicación.

Se nos dio cuando nos hizo a su imagen y semejanza. Se nos dio en la creación, en la Alianza. Pero sobre todo se nos da cuando nos envía al Hijo. Jesús es el Perfecto Comunicador. Él también se autocomunica con nosotros, cuando se encarna para estar más visible a nosotros, cuando muere por nosotros y nos da su misma vida divina hecha gracia, por la que ahora nos hace hijos de Dios.

El hombre es diálogo con Dios trascendente, pero inspirado por Él mismo. Cuando el hombre peca, de nuevo la iniciativa de volver al diálogo viene de Dios, de forma que toda comunicación con el hombre se hace por iniciativa de Dios.

La Biblia es testigo de incomunicaciones y comunicaciones ya desde Adán y Eva, la Babel de la incomunicación, la Alianza... El Cantar de los Cantares cuenta la historia de amor de Dios a Israel y la humanidad. Por eso es el libro cumbre de la Biblia. Por fin llega Jesús, el Comunicador Perfecto, y poco después finalmente la explosión comunicativa de Pentecostés. La Trinidad, Jesús, la Virgen, los Santos... son los modelos de nuestra comunicación.

\section{La Iglesia es comunicación}

Pero Él no quiere que nos relacionemos con Él solamente a nivel individual, sino también como grupo, como comunidad, como Iglesia, con sacramentos comunitarios. La Iglesia es comunicación. El modelo preferido de Iglesia actualmente es el de comunión. Y Dios quiere que nos comuniquemos entre nosotros, y no solamente entre los cristianos, sino entre todos los hombres sin distinción de religión. La Iglesia es diálogo. Debemos comunicarnos con todos, amar a todos, aun a los enemigos. Y la esencia del amor es la comunicación. Así volveremos todos unidos al Padre de quien venimos.

\section{Los medios son dones de Dios}

Nuestra capacidad comunicativa se multiplica ahora con las nuevas tecnologías de los medios, que también son dones de Dios (CP 1; MP). Son buenos a priori (Martini 1991: 14) por haber sido creados por Él. Y son dones de una categoría superior a las 
montañas y rascacielos, pues se relacionan con el plan comunicacional de Dios (Martini 1998: 103). Los medios han sido creados para la unión y fraternidad humanas (CP 1), para que le ayuden al hombre a cumplir su fin de amar a Dios. La exhortación apostólica EN (45) reconoce las posibilidades de los medios para el Evangelio.

El fin primario de los medios es el servicio del género humano, su progreso y su unidad ( $C P$ 12). Comunicar es servir a la verdad y a la realidad; es "servir a los intereses de las mayorías pobres, porque esos son los intereses verdaderos y objetivos de la realidad" (Sobrino 1998: 1). Aunque el publicista usa la comunicación para vender y el político para conseguir votos, el comunicador cristiano la usa para crear progreso y comunidad.

En este sentido todos los pueblos tienen derecho al acceso a los medios de comunicación, pues todos tienen derecho a la unión y al progreso.

Nuestra comunicación tiene ahora muchos canales: comunicación verbal, no verbal, prensa, cine, radio, TV, internet, otras nuevas tecnologías... Son 'dones de Dios' ( $M P, C P, A e N)$ para llevar adelante la comunión y el progreso.

Por esta razón nos debemos adaptar a ellos. Debemos conocer y usar su lenguaje. Debemos estimular la comunicación con los diversos canales. Lo importantes es discernir los criterios de nuestra comunicación (Principio y Fundamento de los EE.EE.).

Pero los medios masivos se usan de una forma distinta: a veces son antisociales y antihumanos. No los aprovechamos de una forma justa: son más los infopobres que los info-ricos. Llega el desequilibrio del pecado, al que se renuncia con firmeza ante la misericordia de Dios ( $1^{\mathrm{a}}$ semana de EE.EE.).

\section{La alegría de tener un Dios comunicativo}

De aquí surge una sensación de alegría, de satisfacción por tener un Dios tan bueno, tan comunicativo, que se nos da así. El me eligió a mí como comunicador para reproducir la imagen del Amado. Vale la pena ir con Él. No nos pasará nada. Nos defenderá. Se preocupará de nosotros. Nos orientará. Nos fiamos de él. Su comunicación sincera y generosa nos ha abierto las puertas del corazón. Lo seguiremos.

\section{Imitando la comunicación de Dios}

Pero no nos podemos quedar ahí. Hay en el hombre un deseo natural de buscar la máxima perfección. Dios lo pide. Una vía es unirse a Dios e imitarlo en todo, también en su estilo de autocomunicación. Dios se nos dio. Quiero hacerme cada vez más consciente de ello y encontrar un camino espiritual para autocomunicarme yo también.

Debemos imitar a Dios en la Encarnación de Dios. En ella Jesús se incultura entre nosotros. La inculturación es un requisito para una buena comunicación. Cristo en su Encarnación se adapta a nosotros para tener una mejor comunicación con nosotros. Nosotros nos ponemos junto a nuestra audiencia, nos encarnamos en ella para comprenderla mejor, para que nos sienta más vecinos a ella (con todas las teorías y técnicas de estudio de recepción y de cercanía).

Debemos ser una continuación de Cristo, comunicadores cristianos. Debemos ser justos, transparentes, comprometidos con la verdad, interculturados, interétnicos. Des- 
cubriendo la identidad de cada uno. Dejando que nuestra audiencia hable. No ser solo la voz de los débiles, sino dejar oir la propia voz de los supeditados y excluidos.

Esta comunicación lleva a la cooperación entre los hombres y esta llevará al progreso. Lo debemos imitar en nuestra comunicación interpersonal y mediática. Así nos creerán.

Así podremos llegar a ser una comunidad y volver todos al Padre, del que venimos.

Jesús se ha encarnado, nos ha mostrado cómo debe ser nuestra vida, cercana a la audiencia, a sus derechos y necesidades. Él es el personaje principal del 'plan' de Dios. Él nos ayuda a dejar de lado todos los egoísmos y seguridades, que encadenan nuestra libertad, y a asumir todo lo que nos identifica con Él (2 ${ }^{\mathrm{a}}$ semana de EE.EE.). Esto no es fácil. Surgen de nuevo las dudas frente a las exigencias de Jesús. Él mismo encuentra problemas, que lo llevan a la muerte ( $3^{a}$ semana de EE.EE.). Pero su pasión y muerte acaban en victoria total. También nosotros venceremos, como Jesús ha vencido en su resurrección. Aquí contemplamos el Misterio Pascual, donde Él se nos da tanto que nos hace hijos de Dios.

Después de volver en este drama al equilibrio, nos entregamos completamente a su servicio con toda nuestra inteligencia, voluntad y corazón ( $4^{\mathrm{a}}$ semana de EE.EE.).

Hay tres elementos en el sueño de amor de Dios sobre mí:

- $\quad$ Dios quiere reinar en mí.

- Dios quiere reinar en mí de forma que todos vivamos como hermanos.

- Dios quiere que seamos fuentes de vida para todos buscando la justicia y solidaridad.

\section{LAS TENTACIONES DEL COMUNICADOR}

Hay tentaciones, debates, preferencias y conflictos en el proceso de la comunicación evangelizadora. Ellos giran principalmente alrededor de qué es lo que debe prevalecer: si el contenido evangelizador u otros elementos. Estos conflictos tienen la raíz en el grado de espiritualidad que se tenga y en la claridad de la misión evangelizadora.

He aquí algunas tentaciones o enfermedades.

La primera prioriza el contenido sobre el lenguaje. La segunda prioriza el lenguaje sobre el contenido. La tercera prioriza la técnica informacional sobre la auténtica comunicación. La cuarta prioriza lo temporal y deja de lado lo eterno. La quinta prioriza el yo sobre el otro. La sexta es secularizante. La séptima olvida los sacramentos.

\section{$1^{\mathrm{a}} \quad$ La tentación del excesivo conceptualismo}

La práctica más común hoy día en la programación religiosa sobre todo institucional es no usar para nada el lenguaje mediático, sino el conceptual y abstracto. Predomina la concepción anticuada de considerar los medios como extensiones del púlpito, sobre todo en cuanto al lenguaje que usan, muy lejano al de los medios. 
Abundan en las radios y televisoras católicas las charlas, las clases magistrales de catecismo y Biblia, donde lo importante es dar contenido, aunque sea de una forma abstracta y poco atrayente. Se descuidan las técnicas de lenguaje, que se verán más adelante. Usan mucho el contenido abstracto del mensaje y no usan lo narrativo e histórico.

Por la formación recibida, muchos, especialmente los clérigos, parten de lo racional, de lo abstracto, haciendo a menudo el programa pesado, poco atrayente, sin color, poco adherente a la vida. Se olvidan del estilo narrativo de la Biblia y de Jesús. No hablan 'con el corazón en la mano'.

Y así mucha programación religiosa pierde sintonía y los medios la retiran, no siempre por una actitud antirreligiosa o secularizante, sino simplemente porque es mala mediáticamente. Más bien los medios aceptarían cualquier cosa, con tal de que esté bien mediáticamente, con tal de que le guste a la audiencia y la haga crecer cuantitativamente.

Ciertamente lo conceptual es necesario. Pero en su momento.

Esta tentación puede venir de una espiritualidad débil, poco profunda, quizá no vivida realmente de corazón. Tales comunicadores se contentan con repetir aburridamente lo que aprendieron en clase. Tienen una fe no encarnada sin consecuencias en la vida real. Hablan como por obligación, sin emoción. Son mentalidades cerradas, que no caen en la cuenta de los cambios que ocurren en la sociedad y de cuál es su papel como comunicador cristiano.

Ante la creciente increencia, Rahner se queja de que los preámbulos de la fe, que se usan en la evangelización, son demasiado racionalistas. Kasper se lamenta de que 'se ha perdido la experiencia religiosa; esto trae consecuencias de un gran alcance' (Walter Kasper 1984: 64, 65, 81).

El encuentro inicial con Dios no se hace a través de tratados racionalistas de teología, sino con algo experimentado y comunicado de persona a persona. Esto es indispensable para la liminalidad y el encuentro inicial.

Jesús comunicaba partiendo de la 'vida', es decir, del sufrimiento, de la necesidad de pan, de agua (como en el diálogo con la Samaritana). El anuncio evangélico debe partir de la vida del hombre para llegar a lo profundo.

Los preámbulos de fe tienen que ser espirituales, culturales y artísticos. Deben ser experiencias que lleguen a la imaginación y al corazón y liberen al hombre invitándolo a niveles más profundos de escucha. Este es el papel de la poesía (no necesariamente la de verso): hacer despertar el sentido del misterio y el deseo por algo más. El comunicador trata de ser poeta, que tiene el don de saber ver dentro e intuir por dónde va la historia. También trata de ser profeta, que asume el deber de 'ser conciencia crítica y catalizadora de la voluntad de conversión'.

La maravilla, la búsqueda, la escucha, la receptividad y la compasión son dimensiones espirituales presentes en cada uno y constituyen la base para la fe. Ellas abrirán caminos hacia lo profundo humano y prepararán así a la fe.

\section{$2^{\mathrm{a}} \quad$ La tentación de priorizar el lenguaje mediático sobre el contenido}

Esta tentación 'linguística' consiste en pensar que el uso del lenguaje mediático bastará para anunciar el evangelio a través de los medios. Hay aquí una preeminencia de 
la técnica lingüística sobre el contenido, del 'cómo' sobre el 'qué', del medio sobre el mensaje. Está el peligro de fiarse más de los medios especializados que del mensaje.

Más adelante se precisarán las diversas características del lenguaje mediático. Aquí solo nos fijamos en unas pocas. El lenguaje mediático es 'sugerente', 'espectacular' y 'teatral', pues trata de emocionar, conquistar, convencer, impactar, impresionar...

Además, a los medios les gusta presentar conflictos para hacerse interesantes. Cualquier noticia la convierten en un parte de guerra. Los temas más pacíficos son presentados con una terminología bélica. Cuando no hay guerras, las inventan con su lenguaje. A veces este lenguaje impide un tratamiento neutral de los temas. Buscan presentar contradicciones y exageraciones. Y a menudo se parcializan.

Cada medio trata de llamar la atención más que la competencia para así "vender' más. Todo está supeditado a la conquista del mayor número de espectadores. Solo les interesa cuánto dinero les llega por la publicidad o qué porcentaje de su mensaje político e ideológico es asimilado por la audiencia.

Los medios tienden a presentar lo que gusta a la audiencia, lo erótico, el mal...

Los medios inclusive cambian el contenido, si con ello logran aumentar la audiencia y los ingresos. Esto explica el aumento de sexo, violencia y sensacionalismo en los medios. "El fin justifica los medios" para ellos.

Hay quienes piensan que el contenido en general, inclusive de los periódicos, ha bajado por este y otros factores.

¿Cómo usar el máximo de técnica lingüística en una programación religiosa, sin que sufra el contenido? "No todo lo que es adecuado a los mass media está en consonancia con el Evangelio de Cristo" (Juan del Río Martín 1999: 7bc).

La comunicación cristiana es diversa de la información de cualquier medio secular. En ella lo que no puede cambiar es el contenido. El comunicador cristiano, al estar inmerso en los medios, debe tener muy claro cuáles son los principios y prioridades de la comunicación religiosa.

La 'tentación de la imagen' da a entender que una gestión profesional de la comunicación y una buena imagen bastan para el anuncio evangélico.

\section{$3^{\mathrm{a}} \quad$ La tentación tecnológica de dar mucha información, pero con poca comunicación}

La tentación 'tecnológica' consiste en pensar que los aparatos y las técnicas de información bastarán para resolver el problema de la incomunicación y de la ausencia de la Iglesia en los medios. ¡Cuántos han conseguido montar una radio o una TV, y después no saben qué hacer con ellos!

Algunos dicen que estamos en "la sociedad de la información". Pero no se puede hablar de sociedad de información y menos de comunicación simplemente por tener más equipos (computadoras, internet...). Más bien solo se ha llegado en algunos sitios a "la sociedad de las técnicas de la información". Las técnicas aumentan empujadas por su oferta de información y por el lucro que generan, pero no crece la comunicación verdadera entre nosotros.

Conviene estar alerta con la ideología técnica. Hay 'mercaderes del templo', que dicen vender comunicación, pero lo que hacen es aprovecharse del deseo de todos por la comunicación para introducir el marketing en la comunicación. 
Además, las empresas que operan en el campo de las nuevas tecnologías son tan grandes que de amos de los medios pueden pasar fácilmente a amos de los contenidos, porque los pueden cambiar por capricho. De la corrupción presente en las empresas de información (Pasquali 2002), poca ética se puede esperar en sus contenidos.

Nuestra aldea global por ahora es solo 'técnica'. Aún no es comunicacional. Hay en ella demasiada heterogeneidad cultural no aceptada por los otros. Es verdad que las técnicas pueden generar mucha información. Pero la comunicación es más que dar muchos datos. Comunicación humana no es lo mismo que comunicación técnica.

La incomunicación humana no se corrige con tecnologías. Algo podrían ayudar, pero hay otros factores más fuertes que la obstaculizan. La brecha entre inforicos e info-pobres aumenta cada día.

El conflicto está entre humanizar la comunicación o tecnificarla.

No basta con informar. Lo que la gente necesita es calidad de comunicación. La gente marginada y reducida a la soledad y al silencio está necesitada de que el comunicador le dé creativamente esperanza, de que le haga sentir calor humano y solidaridad, de que le haga sentir el amor de Dios. Esto se traduce, por ejemplo, en 'ser voz de los que no tienen voz' o mejor aún 'dar voz a quienes no la tienen'.

La comunicación de calidad no es simplemente transmitir, difundir. Esta se puede dar si hay buenos equipos técnicos. Pero la comunicación es más complicada que la técnica.

La comunicación es compartir, es la construcción compartida de significados. En ella siempre hay cariño, respeto, amor. Comunicación es comprensión humana mutua y está unida a la experiencia, a un proyecto, a una acción común, a un compartir de valores. En ella la relación entre personas es más importante que la información en sí. Como siempre, el ser (en relación con otros) es más importante que el tener (la información).

No se debe olvidar que el mejor medio de comunicación es la persona y no la tecnología. A pesar de las nuevas tecnologías, lo que más importa es la persona. Aún son importantes la relación personal, una sonrisa sincera, más tiempo para los demás. La comunicación técnica no debe hacer disminuir la comunicación humana.

Los medios pretenden llamarse medios de 'comunicación'. Algunos lo son. Otros no generan comunicación. Esta requiere una actitud de participar y de responder. No hay auténtica comunicación sin la intención de obtener una respuesta. Esta intención, si es seria, debe empezar mirando con atención la realidad que el otro vive, siente o desea. Pero con mucha frecuencia no se espera la respuesta, porque la información desde el primer momento no considera al que escucha.

Si se quiere hacer comunicación, hay que comenzar enseñando el gusto por la comunicación interpersonal. Esta le sacará de la hipnosis mediática y despertará su identidad y originalidad de persona. Caerá en la cuenta de que uno 'es' en cuanto se da al otro.

Esto se ve mejor en la catequesis. A veces se usa mucho la imagen (la diapositiva, la fotografía, el video, el power point...), y se descuida la fuerza de la palabra personal y convincente del testigo. "El medio es también el mensaje". 


\section{$4^{\mathrm{a}} \quad$ La tentación de la excesiva horizontalidad}

Se hacen con frecuencia sondeos de opinión sobre la credibilidad de las diversas instituciones de un país. Generalmente la Iglesia queda entre las de más credibilidad y aprecio. Pero ¿por qué se le aprecia? Las respuestas varían según los países. En conjunto hay un reconocimiento generalmente alto de las acciones sociales de la Iglesia: educación (Fe y Alegría, escuelas parroquiales, etc.), paz, pobres, lucha por la justicia. Muy al final vienen las actividades vinculadas a la predicación del evangelio y a los sacramentos. Los programas sociales, por tanto, parecen más relevantes que la actividad religiosa.

Asimismo, hay una actitud muy positiva hacia el Papa: a la mayoría le atrae su carisma personal por la confianza colectiva en el papel que desempeña. Solo una minoría dice que ven en él a un mensajero de fe, un símbolo que nos vincula a realidades que exceden nuestras expectativas humanas.

Todos estos sondeos son muy positivos para la Iglesia y el Papa, pero indican un concepto estrecho y erróneo sobre lo que debe ser la Iglesia y el Papa. La culpa es de los entrevistados, pero los medios acríticamente reflejan e informan sobre esta realidad con la misma visión reduccionista: la inmediata, la terrena, la aparente, en una palabra, la horizontal.

Los medios dan un juicio incompleto de las noticias, si no consideran al Dios actuante detrás de lo visible. Debemos "caminar como quien está viendo al Dios invisible" (Heb 11, 27).

El comunicador cristiano tiene el peligro de repetir orgullosamente tales resultados, pero cae en la misma enfermedad excluyente. Los medios presentan lo inmediato y concreto como lo definitivo e irreversible. El comunicador cristiano debe considerar que es más importante mirar las realidades últimas, el destino definitivo de la raza y de la historia humanas. Se requiere tener presente las penúltimas cosas, pero sobre todo las últimas. El comunicador cristiano debe respirar con sus dos pulmones: la profecía junto con la caridad.

¿Cómo fomentar el anhelo por la patria eterna que da sentido a nuestras opciones y a nuestras vidas? ¿Cómo abrir la dimensión vertical en la sucesión horizontal de nuestros días? (Martini 1998: 154-155).

Se podría hacer una encuesta similar de opinión sobre cómo considera el público los medios de la Iglesia o los comunicadores cristianos. ¿Por qué se les aprecia? ¿Porque informan bien, porque permiten la discusión de todo tipo de temas, porque son simpáticos, porque son cercanos a la audiencia, porque se interesan por las necesidades de la gente, porque hablan claro sobre la injusticia, etc.? Ojalá que sea así. Pero ¿cuántos responden: porque me llevan a Dios, porque representan a Dios?

\section{$5^{\mathrm{a}} \quad$ La tentación de la impaciencia y de la prisa por comunicar}

Hoy se vive demasiado de prisa. Las horas de oficina se convierten en carreras contra reloj y contra teléfono. El estrés nos acecha.

Los medios contribuyen a este acoso y a no dejarnos en paz: publicidad exterior en la calle, en las autopistas, entre programas de TV y radio, en sitios web, en las páginas de periódicos y revistas. 
Hay demasiados programas cuyo objetivo central es captar nuestra atención, aunque no digan nada. Solo les interesa conquistarnos como audiencia. Por una parte, este llamar la atención de la audiencia es una de las características del lenguaje mediático (por ejemplo de la publicidad). Por otra, los medios generalmente exageran. A veces son desatentos, precipitados, superficiales y charlatanes.

En la raíz de esta prisa hay una desviación del concepto de comunicar. La comunicación respeta al otro, respeta su ritmo, su libertad. En cambio, la prisa quiere poseer, dominar y explotar al otro. La verdadera comunicación exige espacios de silencio contemplativo, viene de dentro. No se necesitan muchas palabras para comunicar verdaderamente (Martini 1990: 58). Tampoco se necesitan los trucos de la ficción y del ensueño mediático.

La comunicación lleva tiempo. Nadie puede comunicar todo de una vez, precipitadamente o con torpeza. Las comunicaciones de Dios, como la Alianza, se prolongan por siglos. El agricultor es paciente, no fuerza el tiempo de la cosecha, aunque 'siembre con lágrimas' (Salmo 126).

\section{$6^{\mathrm{a}} \quad$ La tentación secularizante}

Secularización significa prescindir de Dios. Ella se nota en el abandono de los símbolos religiosos. No solamente las escuelas se quedan sin crucifijo, sino que van desapareciendo de la conversación ordinaria y de los medios frases como "si Dios quiere", 'Dios quiera', 'Dios dirá', 'gracias a Dios', "providencialmente”, 'milagrosamente'...

Una de las razones de esta pérdida en Occidente puede ser que este se ha centrado en una comunicación precisa, rigurosamente controlada. La ciencia y la tecnología son el mito preferido de hoy; ocupan el primer puesto en las prioridades de cada día. Se prefiere el lenguaje del rigor objetivo para llegar supuestamente a la verdad, aunque nunca se llegue de hecho a ella. Es el método positivista. Este tipo de lenguaje llega a abandonar el lenguaje simbólico y poético.

Frente a esta destrucción y abandono de símbolos religiosos, se necesita una 'construcción y reproducción' contracultural de la fe en el mundo actual.

La fe y la espiritualidad necesitan símbolos. Las palabras son insuficientes para expresar nuestros sentimientos. Pero si no hay sentimientos, tampoco habrá símbolos.

La secularización se distingue de la 'secularidad', que es lo específico del cristiano laico.

"El carácter secular es propio y peculiar de los laicos. (...) A los laicos corresponde, por propia vocación, tratar de obtener el reino de Dios gestionando los asuntos temporales y ordenándolos según Dios” (LG 31).

Se trata de un acento propio (aunque no exclusivo) de los laicos, que contradistingue de modo específico su misión apostólica de la del ministerio ordenado (como el sacerdotal) y la de los religiosos (Uríbarri 2002: 127).

Esto capacita a los laicos de una forma especial a trabajar en los medios de comunicación, que actúan en el mundo secular. Ellos son los principales responsables de vivificar con espíritu humano y cristiano la realidad de los medios. 


\section{$7^{\mathrm{a}} \quad$ La tentación del abandono de los símbolos sacramentales}

Según un estudio realizado sobre los símbolos religiosos de hoy (Martínez-deToda 2000) se ve que los sacramentos han bajado en importancia para los medios y para los universitarios.

La Evangelii Nuntiandi (1975, n. 47) lanzó el grito de alerta por el descuido de los sacramentos. En realidad era un alerta por la pérdida de la fe y de la espiritualidad sacramental. Hace falta replantearla de nuevo. Pero ¿cómo puede el comunicador valorizar los sacramentos en sus mensajes si antes no se viven? Si no hay sacramentos, es que no hay espiritualidad.

"Una espiritualidad auténtica debe poderse comunicar, pues si no es así, de espiritualidad auténtica tiene muy poco" (A. Cencini; cfr. Uríbarri 2002: 146).

Hay un esquema sacramental nuevo, que trata de comprender los signos de la Iglesia no solamente desde arriba o desde su institución (enfoque escolástico), sino desde abajo. Las categorías sacramentales nuevas, que tratan de explicar toda la realidad sacramental, son las siguientes: encuentro, liberación, fiesta, comunicación, celebración, expresión, símbolo, evento, acontecimiento, alianza, historia de la salvación (Ferrándiz 2000: 316). Las tres primeras son enfatizadas por los teólogos especialmente como modelos sacramentales:

El modelo "Encuentro". Trata de que la experiencia del encuentro humano sea eco del encuentro con el misterio santo en el sacramento (Martín Velasco 1995: 8; García Paredes 1991: 124; cfr. Ferrándiz 2000: 325, 334). Está muy cercano a las categorías familia, comunidad, encuentro y diálogo.

El modelo "Liberación". Varios teólogos se han preguntado por qué los sacramentos se han separado de la vida (García Valenceja 1975), por qué entonces han perdido hoy tanto significado para la gente, por qué se han convertido en símbolos 'perdidos' (Castillo 1992: 166; cfr. Ferrándiz 2000: 355).

Le echan la culpa a que antes se practicaban los sacramentos como si fueran ritos sagrados mágicos (Borobio 1991: 468; Floristán y Maldonado 1977: 15). Durante siglos el modelo pastoral predominante era el sacramental, donde lo importante era administrar el sacramento aunque no se le entendiera muy bien (por ejemplo, la Misa en latín).

Hoy hay que explicarlos teniendo en cuenta los signos de los tiempos. Y hoy tales signos hablan de solidaridad, justicia, interés por los pobres, igualdad, fraternidad, derechos...

El símbolo liberador es la cruz de Cristo (su muerte y resurrección). La cruz es el símbolo del crucificado en la tierra y de los procesos de liberación. Pero la Iglesia es también símbolo de la presencia liberadora de Jesús entre los hombres. Ella debe ser también sacramento de liberación del pobre (Maldonado 1991: 245-246). "Lo que hagan por ellos, lo hacen por mí".

El modelo “Fiesta” (Martín Velasco 1982; cfr. Ferrándiz 2000: 374). Esta visión renovada y entusiasta de los sacramentos sería una respuesta ideal a la actual crisis de los sacramentos y a la increencia. Pero "la respuesta radical (a esta increencia) debe estar apoyada en una espiritualidad diferente - más Cristológica, más Trinitaria, más Mariana" (Gallagher 1997: 85).

Evidentemente son necesarios los aparatos, las nuevas tecnologías, la gestión profesional, la buena imagen, el lenguaje mediático, las políticas de comunicación, 
los estudios, los cursos y el deseo de informar, pero no bastan. El contenido no puede ser ahogado por ellos. Ellos deben estar al servicio del mensaje que se quiere transmitir. Deben tener en cuenta la complejidad de la evangelización y la riqueza del mensaje cristiano.

El Sínodo de Obispos de Asia advierte: “Con tantos retos de hoy, pensamos que se debe volver a enfatizar la espiritualidad de quienes están involucrados en la comunicación social. Se ha notado entre los comunicadores de la Iglesia que se sienten entusiasmados por su trabajo profesional, pero que ha bajado su sentido de espiritualidad" (Asamblea especial de los Obispos de Asia sobre la comunicación. Taiwan, nov. 23-28, 1998).

\section{PRIORIDADES ESPIRITUALES DEL COMUNICADOR}

Para vencer las tentaciones y resolver los conflictos indicados se necesita discernir, usar el 'tanto cuanto' ignaciano y elegir lo más importante. Hay tres criterios fundamentales, que se convierten en requisitos que debe tener el comunicador cristiano en este orden de prioridad y de dificultad: debe ser santo, evangelizador y profesional (con el conocimiento del lenguaje y las técnicas mediáticas).

\section{Lo prioritario es ser santo}

Las tentaciones expuestas indican que algo puede fallar o está fallando en la espiritualidad del comunicador. ¿Qué es lo que debe priorizar el comunicador cristiano? ¿Qué es lo más importante en él? ¿La técnica? ¿La ética? ¿El lenguaje mediático? ¿El cómo producir?

El comunicador quiere aprender tantas cosas académicas: teorías, la planificación de la comunicación en su diócesis... ¿Qué debe aprender? ¿Cuál debe ser la preocupación fundamental de sus formadores?

A Salomón Dios le dijo: "Pídeme lo que quieras". El sabio Salomón le pidió: "Dame la capacidad de juzgar bien y de decidir entre lo bueno y lo malo". A Dios le gustó que hubiera pedido 'sabiduría e inteligencia para gobernar a tu pueblo' (I Reyes 3, 5-14). El comunicador necesita sabiduría e inteligencia para comunicar.

Un obispo me contaba glorioso en abril de 2002 que un seglar se le había acercado para decirle que quería estudiar para ser comunicador en la Iglesia. El le contestó: “¡Estupendo! Vaya a estudiar teología”. Verdaderamente, el contenido es más importante que la técnica, el 'qué' es más importante que el 'cómo'.

Sin embargo el 17 de junio de 2002 me hallaba en misa en las "Camere di St. Ignazio di Loyola" en Roma, donde él murió y pasó la mayor parte de su tiempo como General de la recién fundada Compañía di Jesús. De pronto caí en la cuenta de que estaba delante de un gran comunicador.

Ignacio en Manresa, a pocas semanas de su conversión ocurrida en Loyola, y mientras se hallaba sumido en sus "Ejercicios Espirituales", comienza su modo peculiar de conversar con todos sobre cosas de Dios. Esta comunicación interpersonal la continuó en años sucesivos en Barcelona, Alcalá de Henares, Salamanca. En todos esos sitios viene interrogado por las autoridades eclesiásticas y la Inquisición, 
porque hablaba de cosas de Dios sin haber tenido estudios especiales. Esto le da idea de ir a estudiar y obtener el más alto título universitario ('Maestro de Artes') en el lugar más reputado entonces, la Sorbona de París.

En París continúa con su conversación constante y tranquila hasta conseguir sus primeros compañeros entre aquellos universitarios. En Venecia se ordena sacerdote con sus compañeros. En Roma despliega una gran actividad y se conservan más de 5.000 cartas, escritas sobre todo como General de la nueva Compañía de Jesús. También escribe varios libros.

¿De dónde le venía esta fuerza comunicativa? Era un SANTO. Él comunicaba con la fuerza, la convicción y la mansedumbre del santo. Y la verdadera santidad es elocuente, es decir comunicativa.

A otro gran comunicador, compañero suyo, S. Francisco Javier, se le quemaba el pecho por el ardor del amor de Dios. "Basta, Señor, basta", gritaba. Y eso le daba fuerza para buscar y bautizar miles de catecúmenos en la India, para predicar en el Japón y para preparar su entrada en China.

Al seglar que le decía a su obispo que quería estudiar comunicación le añadiría: "Lo más importante es la santidad. Vaya primero a hacer los Ejercicios Espirituales y así puede ser que comience a ser SANTO”.

La característica más importante del comunicador cristiano y de sus formadores es la SANTIDAD, aunque convendría definirla bien dentro de tantos carismas. Y así él debe ser generoso con los demás, debe ser un testigo de la verdad, de la amistad, de la sabiduría y también de Dios. Estamos llamados a ser santos.

Así pues deberán ser intensificados el espíritu de santidad, de autenticidad y de cercanía a los demás, especialmente a los más pobres y necesitados. El Card. Martini (1998: 38) indicó en 1990 algunos ejemplos de "comunicadores de alegría y santidad", cuyos centenarios se celebraban aquel año.

Un joven sacerdote estudiante de comunicación, con quien conversaba sobre la importancia de la santidad en la comunicación cristiana, me interrumpió diciéndome: "Yo sé teología. Estoy estudiando comunicación. Lo que me falta es la santidad".

\section{Aspectos esenciales de la evangelización}

El contenido del Evangelio es precioso y avasallador. Es Jesús mismo que nos dice que Dios es nuestro Padre y que todo en la vida debe ser regulado por el amor, el respeto a los demás, la comprensión, la alegría de ser hijos de Dios... Y Él va por delante con su ejemplo hasta dar su vida por nosotros. Jesús (Dios) se adelanta a mis necesidades. Las satisface antes de que yo se lo pida. Es un amor antecedente y gratuito.

Por eso el cristianismo es algo maravilloso, que nace de la verdad y de la belleza de la autocomunicación de Dios en Jesucristo. Posee una capacidad de seducir al corazón del hombre que no posee ninguna empresa humana.

La vida de Jesús cambia la vida del creyente y le mueve a comunicarlo a los demás... Y así las ricas experiencias de vida de fe y de obras de solidaridad se pueden convertir en noticias que interroguen a los demás... "Lo que os digo en la oscuridad, decidlo al oído; lo que escucháis al oído, proclamadlo desde las azoteas" (Mt 10, 27). "La Iglesia es noticia en la medida en que es acontecimiento, anuncio y proclamación de la Buena Noticia” (Juan del Río Martín 1999: 9b). 
Si esto se da, si esto brilla, entonces podemos formar profesionales y perfeccionar su técnica, etc. Pero sin lo anterior nos engañamos y preparamos nuevas frustraciones. Se necesita conocer las técnicas de la información religiosa, pero sobre todo se necesita conocer bien a Jesús.

Son cuatro los pasos ignacianos del proceso espiritual:

- Conocer bien a Jesús.

- De ahí brotará el 'cariño' por Él. Lo central en la vida espiritual es Jesús, su persona. Lo importante no es su mensaje, como algo conceptual. Lo más importante es enamorarse de Jesús. Y lo más importante en la comunicación cristiana es hacer que otros se enamoren de Él. Esto requiere fijarse en las cosas que harán que me enamore de Jesús, y que harán que otros se enamoren de Él. Lo más importante en el comunicador cristiano es comunicar el amor a Jesús, hacer ver qué bueno es Jesús. Se necesita creer en Él.

- A su vez el amor a Jesús llevará a 'seguirlo y servirlo', especialmente en la comunión con los demás y con los más necesitados.

- Esto hará que se le podrá 'imitar' en las afrentas, pobreza, humillaciones, que es el más alto nivel de humildad-santidad (S. Ignacio de Loyola, Ejercicios Espirituales, nn. 104, 109, 98).

De aquí viene espontánea el comunicar Jesús a los demás. El interés por las técnicas de la comunicación tiene que subordinarse a estos cuatro pasos del proceso espiritual y a la primacía del amor a Jesús y a su mensaje. Lo único que tiene que hacer el comunicador es llevar esto a la gente de forma convincente. Lo importante no es la técnica, sino el convencimiento. Lo demás es accesorio. En Pentecostés Pedro hablaba en su lengua, pero todos los extranjeros le entendían. Y muchos de ellos se convirtieron solo con su palabra.

Cuando daba el P. Arrupe (General de la Compañía de Jesús) catequesis de adultos como misionero en Japón, un viejo japonés le miraba sin pestañear y sin que durante seis meses dijera una palabra ni a favor ni en contra. Arrupe, extrañado, se atrevió un día a preguntarle: "Que opina usted de mis explicaciones?". El japonés respondió: "No puedo opinar porque no he oído nada. Soy completamente sordo. Pero me basta con mirarle a los ojos. Usted no miente. Lo que usted cree, eso creo yo". Arrupe vivía realmente e irradiaba lo que predicaba. Estaba convencido de que evangelizar antes que hablar es 'ser', como explica en una charla a los seminaristas de la India.

El futuro de la fe está ligado a la experiencia de Dios. No está ni estará en dar doctrina, prácticas o ritos.

La vocación fundamental del comunicador cristiano es la comunión y la nueva evangelización. Ella solo puede venir de un corazón entregado al evangelio y de un conocimiento de los nuevos lenguajes de los medios. He ahí la vida interna del comunicador. La oración humilde y arrepentida al Señor ayudará a ambos requisitos.

La evangelización tiene muchas formas y etapas: es directa e indirecta, explícita e implícita. Hay preevangelización, evangelización y posevangelización. Hay enfoques 'personalistas' de la fe. Hay otros más sociales y horizontales. Los tipos de evangelización dependerán del tipo de espiritualidad, que predomine en el comunicador. 
La evangelización es compleja, difícil y exigente porque compromete. La Redemptoris Missio (1990, n. 41) indica seis dimensiones de la evangelización en este orden de preferencia:

1. Testimonio de vida. (También en $E N$ 1975, n. 41). Lo más importante es creer fuertemente en lo que se dice y en cumplirlo y vivirlo. Así lo exigen los jóvenes chilenos (Lagomarsino y Zarzuri 1998; Martínez-de-Toda 2000). Se necesita la santidad.

No puede haber contradicción entre lo que anuncia el evangelizador y su vida profesional y personal. Si no, cae su credibilidad.

El compromiso evangelizador no es simplemente transmisión de doctrina. Los medios de comunicación social modifican las leyes de credibilidad de cada mensaje y de cada institución: la personalidad del testigo tiene un peso mayor que el contenido de su testimonio.

2. Proclamación y anuncio explícito de Jesús, rostro del Padre. Lo central en el evangelio es el Reino de Dios, y el Reino es Jesús mismo. El proyecto central de lo que se quiere comunicar es Jesús mismo, el Señor; y en la alegría de su presencia viva delante de Él haremos más y más proyectos de comunicación que toquen a todos. De la fe en Jesús y su mensaje surgirá la palabra expresa caliente y convincente para comunicarlo. (También en EN, n. 42).

3. El objetivo es la conversión total del individuo y de la sociedad: una conversión de valores, actitudes y conductas.

4. Inculturación y contextualización del evangelio. Esto exige un discernimiento previo para ver qué valores culturales se parecen más a los del evangelio para fomentarlos.

5. Formación de iglesias locales.

6. Promoción humana y de la justicia. Dios quiere reinar de forma que todos vivamos como hermanos. En torno a Jesús el hombre recupera todas sus dimensiones. La gloria de Dios es la plena humanización del hombre. La gloria de Dios es que el hombre viva ( $\mathrm{S}$. Ireneo). El comunicador no puede pasar de largo junto a esa mayoría de excluidos, que se quedan al borde del camino, después de haber sido robados y apaleados. No puede hacer como el sacerdote y el levita de la Parábola del Samaritano. (Comunicador, ¿quién es tu prójimo?).

La evangelización tiene además los siguientes seis prerrequisitos pedagógicos (para una explicación mayor ver Martínez-de-Toda 2001).

1. Usar el diálogo y las relaciones personales con cada evangelizado. (También en $E N$, n. 46).

2. Conocer su situación y necesidades personales.

3. Orientarlo a una elección personal, libre y consciente. En la evangelización conviene respetar el ritmo del otro. No puede uno acercarse a una persona sin respetar su subjetividad, sin iniciar un diálogo respetuoso, que permita una comunicación auténtica.

4. Insertarlo en una comunidad o grupo. (Sínodos de los Obispos italianos 1974 e 1977). 
5. Apelar a todo el hombre: no solamente a sus aspectos sensibles y emocionales, sino aun a los intelectuales.

6. Usar los medios masivos en el proceso evangelizador ( $E N$ 1975: N. 45). Ello exige conocer las técnicas necesarias para comunicar el mensaje cristiano en la cultura contemporánea.

Tales dimensiones y requisitos pedagógicos exigen una fuerte espiritualidad.

\section{Las técnicas mediáticas en la evangelización}

El Espíritu Santo puede repetir el milagro de Pentecostés con nosotros de forma extraordinaria. Sin embargo Dios usa nuestros medios humanos. El Evangelio necesita ciertas técnicas de presentación. Si se usan los medios masivos, estos tienen sus técnicas específicas, sumamente ricas, que son imprescindibles. El comunicador cristiano las debe conocer.

La misma Redemptoris Missio reconoce la importancia del estudio del lenguaje mediático: "No basta, pues, usarlos para difundir el mensaje cristiano y el Magisterio de la Iglesia, sino que conviene integrar el mensaje mismo en esta "nueva cultura" creada por la comunicación moderna. Es un problema complejo, ya que esta cultura nace, aun antes que de los contenidos, del hecho mismo de que existen nuevos modos de comunicar con nuevos lenguajes, nuevas técnicas, nuevos comportamientos sicológicos" (Juan Pablo II. Redemptoris Missio 1990, n. 37c).

He aquí las principales características del lenguaje audiovisual (de la radio, TV y cine). El lenguaje audiovisual es emotivo, dramático (con sus dos elementos más importantes: conflicto e identificación de la audiencia con el personaje principal), narrativo, entretenido, espectacular (con el uso de grandes escenarios y de personalidades famosas), imaginativo (estimulando la imaginación con símbolos), excita la curiosidad, es hábil para responder a tiempo las preguntas más profundas y espontáneas de la gente. (Una explicación mayor de tales características se halla en Martínez-de-Toda 2000b). El lenguaje del internet participa de estas características pero añade su peculiaridad de poder ser interactivo.

Por su parte el lenguaje audiovisual religioso también tiene sus propias características y formas: mítico, ritual, liminal, narrativo, simbólico, artístico y estimula la búsqueda de respuestas sobre el sentido de la vida. Es también agradable (y lúdico), fascinante, pluralista, universal, con novedades, atento a las necesidades de la audiencia, visual y se encuentra también en el mismo medium. Hay que expresarse sobre todo con el corazón en la mano, con los ojos, con la expresión, con los gestos, con nuestra actitud, con nuestra personalidad..., como lo haría Jesús, que ejercía tanta atracción entre todos. El reto es hacer del medio el mensaje, convertir el medio en mensaje.

El instrumento de comunicación, más rico y más pobre al mismo tiempo, es la persona del anunciador. La comunicación es verdadera y eficaz si transmite una experiencia de Dios. Si esta nace de la comunión con Él llega a ser comunión con los otros.

El género más apto para la comunicación religiosa es el testimonio contado como experiencia religiosa en forma de narración, drama o entrevista. 


\section{LA PRÁCTICA DEL COMUNICADOR CRISTIANO}

La espiritualidad no puede quedar reducida "a contenidos espirituales (mal entendidos como realidades etéreas, intemporales, ahistóricas)... El espíritu es ante todo 'viento', 'fuerza' (spiritus, pneuma), con que los humanos configuramos todo lo que somos y todo lo que hacemos y también la comunicación” (Sobrino 1998: 1).

\section{Indicadores de la espiritualidad del comunicador cristiano}

La espiritualidad tiene dos indicadores, la oración y la acción. Ellos acreditan si fue asimilado o no el proceso de la autocomunicación divina y reflejan el grado de respuesta del hombre a tal autocomunicación.

La oración, entendida como reflexión personal, contemplación, meditación, examen de conciencia, es comunicación 'intrapersonal'. La oración, entendida como diálogo interior, por el que nos comunicamos con el Padre, el Hijo, el Espíritu Santo, la Virgen, los Santos, etc. se puede llamar comunicación 'traspersonal'.

Juan Pablo II anima a los comunicadores cristianos a promover esta comunión entre todos a través de una oración, con la que puedan entrar en comunión con el Espíritu de Dios.

La oración es necesaria. Hablar de Dios requiere hablar con Dios. Un proverbio indio dice: "No dejes que crezca la hierba en la senda que va de la puerta de tu casa a la de tu amigo". Cuanta más alta y más grande la responsabilidad, más hay que rezar. La responsabilidad del comunicador es muy grande. Antes de que el comunicador presente a Jesús al hombre, antes de que piense en qué y cómo comunicarlo, debe pedirle a Él que le enseñe a comunicarlo. La oración debe preceder el acto de comunicar y también lo debe completar.

La oración se necesita para comunicar, para ser uno mismo. Así el mensaje se hallará en todo nuestro ser, en todos nuestros sentidos, en nuestra convicción. El desafío de la comunicación cristiana es convertir el medio en el mensaje. Lo que importa es el ser. Ahí está el mensaje, que la televisión recoge en detalle. A través de nuestra apariencia el telespectador intuye nuestro ser, nuestra forma de pensar. El mensaje no solo se halla en nuestras palabras, sino en todos nuestros movimientos. Más que llamarse uno ‘católico' o ‘cristiano', lo importante es ser uno mismo.

Toda espiritualidad comprende también la acción que dimana de ella. La acción comprende conocimientos, actitudes y conductas. Los conocimientos ayudan a formar actitudes y estas pueden manifestarse en conductas a través de las virtudes.

Ambos indicadores (oración y acción) deben coexistir. No se puede tener un activismo, que suprima la contemplación, que es la tentación de tantos.

\section{Virtudes del comunicador cristiano}

El Espíritu Santo da a individuos y comunidades sus dones de fe, esperanza y caridad (1 Cor 13, 13) (virtudes teologales), sabiduría, entendimiento (Col 1, 9), y libertad (Rom 8, 21; Gal 5, 13, 2 Cor 3, 17). También da frutos, como el amor, la alegría, la paciencia ( $\mathrm{Tel} 5,23-24)$, y los carismas de diferente tipo que construyen la comunidad cristiana (1 Cor 12, 4-11, 28-30; Rom 12, 6-8; Ef 4, 11-13) (Principe 
1993: 932). Hay otras virtudes también relacionadas con la comunicación: comunión, progreso, unión, participación, libertad de expresión, atención especial a los débiles, creación de cultura, horizontalidad, respeto a los demás... El comunicador cristiano practica la comunión y la unión y empuja hacia ella.

El resultado final es una comunidad de fe, que se proyecta hacia el exterior hasta que todo el mundo sea comunión y pueda así unida retornar al Padre, a la Trinidad.

El ideal de vivir en una sociedad, donde haya una auténtica comunicación entre todos los seres humanos, parece coincidir con el ideal del cristianismo por formar una comunidad en los diversos niveles familiar, grupal, comunitario, social, regional y mundial. Se desea conocer qué aporta la Iglesia dentro de su vocación más espiritual y qué aporta la espiritualidad cristiana a este ideal.

\section{Las palabras claves de la espiritualidad del comunicador}

Hice una pequeña investigación sobre la espiritualidad de nuestros estudiantes del CICS (Centro Interdisciplinar de Comunicación Social) en la Gregoriana en uno de mis seminarios (el 13 de marzo de 2002).

Hice esta pregunta: "Elijan las ocho palabras que para ustedes describan mejor la espiritualidad del comunicador cristiano".

En el seminario había 13 estudiantes, distribuidos así: 6 laicos/as, 5 sacerdotes y 2 monjas. Venían de Guinea, Mali, Congo, India, Bosnia, Brasil, Perú, Haití y Venezuela. Estos son los resultados de las Palabras-clave (o conceptos-clave).

La palabra más mencionada fue 'verdad' (9 veces). Después se mencionaron las siguientes palabras: ánimo (7), amor (6), testimonio (6), comunión (4), profesionalidad (4), oración (4), solidaridad (4), alegría (3), caridad (3), fe (3), transparencia (3), apertura (2), dignidad (2), justicia (2), libertad (2), servicio (2), voluntad (2). Las siguientes palabras solo aparecieron una vez: amistad, atención, coherencia, compromiso, comunidad, conciencia, creatividad, diálogo, disponibilidad, eficiencia, entusiasmo, gracia, gratuidad, honestidad, humildad, interculturalidad, interioridad, interreligiosidad, mediación, paciencia, palabra, progreso, respeto, sabiduría, sinceridad, tenacidad, Trinidad, valor.

Estas palabras constituyen la vivencia espiritual de estos estudiantes de comunicación.

\section{Niveles del profesional comunicador cristiano}

A modo de resumen se pueden distinguir cuatro niveles de comunicadores de peor a mejor en cuanto al grado de integración del espíritu evangelizador, la técnica y su propia conducta. Se deja de lado el que es meramente técnico, es decir, conoce a maravilla el funcionamiento de los aparatos, pero no tiene una visión integrada de su labor. Esta sería la escala del profesional:

$1^{\circ}$ El profesional ético y defensor de la VERDAD. El profesional, si no es ético, no es profesional. El profesional mediático conoce muy bien el lenguaje mediático, sabe cuándo usarlo y actúa según una 'ética profesional', quizá aún demasiado minimalista sin preocuparse demasiado por el contenido. Debe conocer la cultura contemporánea. 
El comunicador cristiano, como todo profesional de la comunicación, debe cumplir la autorregulación periodística. Debe seguir la ética del periodista. Debe tener en cuenta las tres categorías axiológicas (éticas) básicas, que son verdad, libertad y justicia. Ellas corresponden a los valores fundamentales del evangelio, que, según un estudio publicado en La Croix son: libertad, dignidad, justicia, paz y amor. Debe defender los valores humano-cristianos, respetando la dignidad de los otros y sus derechos. Debe tener integridad.

"Las nuevas situaciones por las que pasan nuestros países requieren un discernimiento profundo y exigen un espíritu de búsqueda de la verdad" (Sobrino 1985: 16-19). Precisamente la misión del comunicador es manifestar la verdad sin encubrirla jamás (Sobrino 1998), pero haciéndolo discretamente y con amor. Esto trae persecuciones, que exigen un espíritu de fortaleza y de santidad para purificarse en la búsqueda de la verdad con amor.

El buen profesional necesita sobre todo escuchar. Necesita educarse para la comunicación auténtica. Debe saber comunicarse con los demás a nivel interpersonal. Así podrá participar y colaborar también con otras áreas de la pastoral (AeN, N. $28,30)$. Necesita ir más adentro de sí mismo para encontrar a Dios. Esta comunicación intrapersonal y traspersonal le hará encontrar el compromiso y la fuerza que le lleve a una mejor comunicación interpersonal, grupal y masiva con los demás.

Esto es parte de la 'comunicación interpersonal' o cara a cara. En ella se distinguen diversos géneros. A la conversación (o diálogo exterior) se le llama el género medio (cfr. Martini 1991: 15). En los extremos se halla por una parte la clase magistral (o alocución en monólogo), y por otra la crítica (murmuraciónchismorreo). A su vez el diálogo tiene diversos niveles de profundidad: desde el simple saludo hasta hablar de corazón a corazón. Generalmente en internet no se va muy profundo.

$2^{\circ}$ El profesional ético, pero que además es un cristiano practicante, aunque quizá con poca preparación teológica. Debe vivir la relación Fe-Justicia (que incluye la de Fe-Verdad), Fe-Cultura (general y de los jóvenes), hacer Diálogo Interreligioso.

La vida profesional del comunicador cristiano debe ser complementada por una vida privada de 'fe y obras' (S. Pablo), de una vida intachable y ejemplar, como la de cualquier cristiano. Debe ser una persona de sacramentos. Debe ser fiel al evangelio y a la Iglesia, con opción por los pobres y eligiendo lo que Jesús elegiría hoy.

$3^{\circ} \mathrm{El}$ profesional conocedor de alguna teología. El buen periodista debe tocar todos los temas posibles desde también todos los ángulos posibles, también el religioso. Esto exige una formación religiosa y teológica.

$4^{\circ} \mathrm{El}$ profesional apóstol y santo, siempre dispuesto a aprovechar cualquier oportunidad para anunciar explícita e implícitamente el mensaje cristiano. Está lleno del celo apostólico por predicar la Palabra y sabe cómo insertarla en la cultura actual.

\section{Preguntas para reflexionar, conversar y profundizar}

¿Hablo y actúo como si no estuviera enterado del deseo comunicador de Dios con nosotros? Como resultado de mi comunicación con la gente, ¿esta se comunica mejor con Dios?

¿Estoy convencido de que la oración es el primer instrumento y el más importante para comunicarme de forma seria y constructiva con los otros? (Martini 1998: 
158). He aquí algunos consejos de Lafrance (1989: 140): No leas el periódico ni veas la televisión como un turista, sino busca comunicarte con todos esos, a quienes solo conoces por los medios de información. Tu oración se enriquecerá con toda esta vida del mundo presentada en los medios. Ella pedirá por quienes sufren espiritual y materialmente. Comprenderás que a muchos lo que les falta no es medios, sino la razón para vivir.

¿Cómo se reflejan los principios de la espiritualidad comunicacional en la experiencia comunicacional de Cristo? ¿Cómo los podemos asimilar en nuestro contexto secularizado? ¿Cómo podrías explicar a otros comunicadores la espiritualidad del comunicador? ¿Qué es lo que más te mueve a ser comunicador cristiano? ¿Cómo formularías los mandamientos del comunicador cristiano? ¿Cuál es mi papel como comunicador cristiano?

¿Sería conveniente que te relaciones de una manera sistemática con otros comunicadores cristianos? Seguramente habrá otros también interesados en la espiritualidad del comunicador. Esta relación servirá para compartir ideas, sentimientos, compromisos, planes... y así poder incrementar una espiritualidad comunicacional. ¿Se podrían tener algunas actividades conjuntas, como retiros conjuntos, una Misa al mes juntos, reuniones para estudiar algún problema concreto? ¿Cómo integrar este grupo en SIGNIS y UCLAP?

\section{CONCLUSIÓN}

Se han indicado las características generales de la espiritualidad del comunicador cristiano. Quedan otros muchos interrogantes. Por ejemplo, ¿cómo alimentar la espiritualidad comunicacional? También hay posibles trabajos ulteriores de desarro1lo, como: modelos de la espiritualidad del comunicador cristiano, la espiritualidad del comunicador cristiano según el camino ignaciano, los Ejercicios Espirituales del comunicador...

\section{BIBLIOGRAFÍA}

Alphonso, Herbert (1994) Living our Spirituality in Depth and in a Uniquely Personal Way. Rome: Religious of Jesus and Mary Generalate.

Anselmo de Canterbury, Proslogion prooemium: PL 153, 225A, como está citado en el Catecismo de la Iglesia Católica 1992, n. 158. Getafe (Madrid): Asociación de Editores del Catecismo.

Arroyo, Gonzalo; Silva, Joaquín; y Verdugo, Fernando (1992) Por los caminos de América... Desafíos socio-culturales a la nueva evangelización. Santiago de Chile: Paulinas.

Au, Wilkie (1989) Por el camino del corazón. Hacia una espiritualidad cristiana holística. Santiago de Chile: Criterio y Paulinas.

Berendt, Joachim-Ernst (1983) Nada Brahma, Franckfurt.

Berman, Marshall (1981) Todo lo sólido se desvanece en el aire. La experiencia de la modernidad. Madrid: Siglo XXI. 
Boff, Clodovis (1998) Teoria del metodo teologico. Versione didattica. Padova: Ediz. Messaggero. (Hay una edición en portugués con algunos cambios).

Borobio, D. (1991) “¿Qué es un sacramento?”, en Borobio, D., ed, La celebración en la Iglesia. Liturgia y sacramentología fundamental, vol I, Salamanca: Sígueme, 361-536.

Brugger, Walter (1988) Diccionario de filosofía. Barcelona: Herder.

Castillo, J.M. (1992) Símbolos de libertad. Teología de los sacramentos, Salamanca: Sígueme.

Del Río Martín, Juan (Obispo de Jerez de la Frontera) (1999) "Naturaleza e inserción pastoral de las Delegaciones Diocesanas de Medios de Comunicación Social”. En MCS, Boletín de la Comisión Episcopal de Medios de Comunicación Social (España), No 198, octubre - diciembre 1999, pp. 5-12.

Durkheim, Emile (1975) Durkheim on Religion: A selection of readings with bibliographies and introductory remarks. W. S. F. Pickering ed. London: Routledge and Kegan Paul.

Ferguson, Marilyn (1981) Die sanfte Verschwörung. Persönliche und gesellschaftliche Transformation im Zeitalterdes Wassermanns, Basel.

Ferrándiz García, Aurelio (2000) Los diferentes modelos sacramentológicos en la reflexión teológica española del posconcilio. Roma: PUG (tesis).

Floristán, C. y Maldonado, L. (1977) Los sacramentos, signos de liberación. Madrid: Fundación SM.

Freud, Sigmund (1975) The Psychopathology of Everyday Life. Volume 5 of the Pelican Freud Library. Harmondsworth: Penguin.

. (1985) Civilization, Society and Religion: Group Psychology, Civilization and its Discontents and other works. Penguin Freud Library. Vol. 1. Translated from the German under the general editorship of James Strachey. Volume editor Albert Dickson. Harmondsworth: Penguin.

Gallagher, Michael Paul (1997, 1998) Clashing symbols, New York 1998; London 1997.

García Valenceja, J.J. (1975) "Por qué el sacramento es, demasiadas veces, incomprensible y distante", en Sal Terrae 63 (1975), pp. 349-353.

Goffi, Tullo (1987) La experiencia espiritual hoy. Líneas esenciales de la espiritualidad cristiana contemporánea. Salamanca: Sígueme.

Hardy, Alister (1984) La naturaleza espiritual del hombre. Estudio sobre la experiencia religiosa contemporánea. Barcelona: Herder.

Haughey, John C. (1973) The Conspiracy of God: The Holy Spirit in Men. Garden City, NY: Doubleday.

Kasper, Walter (1984) The God of Jesus Christ, London.

Kelly, John R. (1983) Leisure Identities and Interaction. London: George Allen and Unwin.

Kolvenbach, Peter-Hans (1998) Opciones y Compromisos. Caracas: UCAB.

Lacugna, Catherine Mowry, and Downey, Michael (1993) "Trinitarian Spirituality", in Michael Downey, ed. The New Dictionary of Catholic Spirituality. Collegeville, Minnesota: The Liturgical Press.

Lafrance, J. (1989) Prega il Padre nel segreto, Milano: O.R.

Lagomarsino B., Mario, y Zarzuri C., Raúl (1998) Espiritualidad, Televisión Abierta y Juventud. Santiago de Chile: CENECA. 
Larkin, Ernest E. (1998) "Spiritualità", en L. Borriello, E. Caruana, M.R. del Genio, y N. Suffi, a cura di, Dizionario di mistica, Città del Vaticano: Vaticana, pp. 1170-1172.

Martín Velasco, J. (1995) El encuentro con Dios. Madrid: Caparrós.

Martínez, Germán (1993) "Hispanic-american spirituality”, in Michael Downey, ed. The New Dictionary of Catholic Spirituality. Collegeville, Minnesota: The Liturgical Press.

Martínez-de-Toda y Terrero, José (2000a) “Jóvenes, medios y espiritualidad”. Actas del III Congreso Internacional "Cultura y Medios de Comunicación”. 15-18 febrero 1999. Salamanca: Universidad Pontificia de Salamanca. Pp. 753-765. Mag 691 K 208.

.(2000d) "Religious symbols in mass media", 22nd Conference of the IAMCR (International Association of Mass Communication Research), in Singapore, 17-20 July 2000.

- - (2001a), Come realizzare programmi religiosi ed educativi alla radio, alla televisione ed in internet. Roma: PUG.

.(2001b) La pubblicità come espressione della cultura contemporanea. Roma: Pontificia Università Gregoriana.

___. (2001c), “Teología y comunicación en los documentos de la Iglesia”. Congreso Internacional sobre “Iglesia y MCS”. Univ. Católica 'S. Antonio' de Murcia (UCAM), 20-21 octubre 2000, España.

_- (2001d) "A new religiosity through media". $3^{\text {rd }}$ Int. Conference on "Media, Religion and Culture", Edinburgh, July 20-23, 1999.

Martini, Carlo Maria (1991) Camminare sulla seta. La comunicazione nel ministero pastorale. Milano: Àncora.

- - (1998) Comunicar a Cristo hoy. Salamanca: Universidad Pontificia de Salamanca. Ahí se hallan traducidas sus cartas Effatà "Apriti” (1990) e Il lembo del mantello (1991).

Marx, Karl (1963) Selected Writings in Sociology and Social Philosophy, edited by T. B. Bottomore and Maximilian Rubel. Harmondsworth: Pelican.

—_. Das Kapital. Translated by Ben Fowkes. London: Penguin

Matanic, A. (1983) "Espiritualidad", en Ermanno Ancilli, ed. Diccionario de espiritualidad.

Barcelona: Herder.

Mynarek, Hubertus (1983) Religiös ohne Gott? Neue Religiösität der Gegenwart in Selbstzeugnissen.

O'Collins, Gerald (1993) Il ricupero della teologia fondamentale, Città del Vaticano.

Pasquali, Antonio (2002) "La 'Sociedad de la Información': un antecedente penal", en ALAI (América Latina en movimiento), No 355, 2 julio 2002, pp. 12-16.

Principe, Walter H. (1993) "Christian Spirituality", in Michael Downey, ed. The New Dictionary of Catholic Spirituality. Collegeville, Minnesota: The Liturgical Press.

Sachs, John R. (1990) "Trinity and Self-Communication: God's Mystery and Ours".

Sobrino, Jon (1985) Liberación con espíritu. Apuntes para una nueva espiritualidad. Santander: Sal Terrae.

—_. (1998) Comunicación y espiritualidad: Liberación de la verdad oprimida. Foro Internacional: Comunicación y Ciudadanía. 9-11 septiembre 1998. El Salvador. 
Sudbrack, Josef (1990) La nueva religiosidad. Un desafío para los cristianos. Madrid.

Thorn, William (1996) "Models of Church and Communication", en Media, Culture and Catholicism, ed. Paul A. Soukup. Kansas City: Sheed and Ward.

Uríbarri, Gabino (2002) "Religiosos y laicos en una Iglesia comunión" CONFER (Conferencia Española de Religiosos), Revista de la Vida Religiosa. Volumen 41, No 157 , enero-marzo 2002, pp. 113-151

Weber, Max (1968) Economy and Society: An Outline of Interpretive Sociology. New York: Bedminster Press.

SIGLAS (Documentos de la Santa Sede)

CP Communio et Progressio (Instrucción Pastoral de la Comisión Pont. Com. Soc.) (1971)

DV Dei Verbum (Constitución Dogmática del Vaticano II sobre la revelación divina) (1965)

AeN Aetatis Novae (Instrucción Pastoral del Pont. Consejo de las Comunic. Soc.) (1992)

EN Evangelii Nuntiandi (Exhortación Apostólica de Pablo VI) (1975)

IM Inter Mirifica (Decr. conc. del Vat. II sobre los instrumentos de comunic. social) (1963)

LG Lumen Gentium (Constitución Dogmática del Vaticano II sobre la Iglesia) (1964)

MP Miranda Prorsus (Encíclica de Pío XII) (1957)

\section{Documentos del CELAM}

Medellín, II Conferencia General del Episcopado Latinoamericano, en Medellín (1968) Puebla, III Conferencia General del Episcopado Latinoamericano, en Puebla (1979) Sto. Domingo, IV Conferencia General del Episcopado Latinoamericano, en Sto. Domingo (1992)

\section{RESUMEN}

La comunicación religiosa a través de los medios tiene problemas. El mensaje cristiano mediático no está llegando al público. Estos problemas levantan interrogantes: ¿Cómo debe ser el comunicador cristiano? ¿Cuáles deben ser sus características? ¿Qué motivaciones debe tener? ¿Qué vida interior debe tener para que pueda comunicar eficazmente?

Aquí se presenta la espiritualidad como algo que debe impregnar toda la misión de comunicador. Ella es elemento fundamental de la comunicación cristiana y el alma del comunicador cristiano. No puede haber una dicotomía entre la profesión de comunicador y su vida interior. Ambas deben enriquecerse e integrarse mutuamente.

Primero se explicará lo que se entiende por 'espiritualidad' en general, sus características, el contexto en que se halla la espiritualidad latinoamericana y la necesidad que el comunicador cristiano tiene de desarrollar su propia espiritualidad. 
Después se buscarán los elementos teológicos en que se basa la espiritualidad del comunicador. Se verán el camino espiritual del comunicador y las características más concretas de la espiritualidad del comunicador cristiano.

Se indicarán las tentaciones más comunes en el comunicador cristiano: expresarse de una forma conceptual; priorizar la técnica y el lenguaje mediático sobre el contenido (con las tentaciones 'tecnológica', 'mediática' y 'profesional'); la prisa por comunicar y el abandono de los símbolos sacramentales.

Ellas obligan a buscar las prioridades espirituales del comunicador cristiano, que le permitan hacer un discernimiento. Estas son: el comunicador debe ser santo, evangelizador y profesional (con el conocimiento del lenguaje y las técnicas mediáticas).

Finalmente se especificará cómo la espiritualidad del comunicador cristiano se da en la práctica. Se señalan sus indicadores (oración y acción), sus virtudes (como dones y frutos del Espíritu Santo), las palabras claves de la espiritualidad del comunicador y los niveles del profesional comunicador cristiano.

\begin{abstract}
The religious conimunication in the media faces problems because the Christian mediate message does not reach the audience. This raises some questions such as: What should the Christian communicator be like? What characteristics should he have? What should his drive be? What interior life should he have to coinmunicate efficaciously? This article presents the spirituality as something that should drench the mission of the communicator, as the essential element of the Christian communicator. There should be no dichotomy between his profession and his interior life, but both should enrich each other.

The article explains what is meant by 'spirituality' and its characteristics. The context in which the Latin American spirituality stands, and the need for Chrisfian communicators to develop their own spirituality.

The theological foundations on which such spirituality should be based will be sought, regarding the characteristics of the communicator's spiritual path. The articte indicates the most common temptations of the Christian communicator: expressing himself in a conceptual manner, giving priority to the technique and language rather than the content, the rush to communicate, and the Withdrawal of the sacramental symbols. These temptations force us to seek the priorities which will allow the Christian communicator to discern properly. These are: the communicator has to be a holy person, an evangelizer and a good updated professional.

Finally, the way such spirituality is applied in the practice, through its indicators (prayer and action) his virtues (as gifls and fruits of the Holy Spirit), the key spiritual words and levels of the professional Chrisfian communicator.
\end{abstract}

